\title{
Towards the Use of a Smartphone Imaging-Based Tool for Point-of-Care Detection of Asymptomatic Low-Density Malaria Parasitemia
}

\section{Ashlee Joi Colbert ( $\square$ Colberta@purdue.edu )}

Purdue University Weldon School of Biomedical Engineering https://orcid.org/0000-0002-7871-4084

\section{Katrina Co}

Indiana University School of Medicine

Giselle Lima-Cooper

Indiana University School of Medicine

\section{Dong Hoon Lee}

Purdue University Mechanical Engineering: Purdue University School of Mechanical Engineering

\section{Katherine Clayton}

OmniVis

\section{Steven Wereley}

Purdue University Mechanical Engineering: Purdue University School of Mechanical Engineering

Chandy John

Indiana University School of Medicine

Jacqueline Linnes

Purdue University Weldon School of Biomedical Engineering

\section{Tamara Kinzer-Ursem}

Purdue University College of Engineering

\section{Research Article}

Keywords: malaria, particle-diffusometry, nucleic-acid based tests, smartphone-detection, LAMP-assay

Posted Date: March 22nd, 2021

DOI: https://doi.org/10.21203/rs.3.rs-335992/v1

License: (c) (1) This work is licensed under a Creative Commons Attribution 4.0 International License.

Read Full License 
Title: Towards the use of a smartphone imaging-based tool for point-of-care detection of asymptomatic low-density malaria parasitemia

Ashlee J. Colbert ${ }^{1}$,Katrina Co ${ }^{2}$, Giselle Lima-Cooper ${ }^{2}$, Dong Hoon Lee ${ }^{3}$, Katherine N. Clayton ${ }^{4}$, Steven T. Wereley ${ }^{3}$, Chandy C. John ${ }^{2}$, Jacqueline C. Linnes ${ }^{1 *}$, and Tamara L. Kinzer-Ursem ${ }^{2 *}$

${ }^{1}$ Weldon School of Biomedical Engineering, Purdue University, West Lafayette, IN, 47907, USA,

E-mail: jlinnes@purdue.edu ; tursem@ @urdue.edu

${ }^{2}$ Indiana University School of Medicine, Indiana University, Indianapolis, IN, 46202, USA

$11{ }^{3}$ School of Mechanical Engineering, Purdue University, West Lafayette, IN, 47907, USA

$12{ }^{4}$ OmniVis Inc., Indianapolis, IN, 46201, USA

Keywords: malaria, particle-diffusometry, nucleic-acid based tests, smartphone-detection,

\section{Abstract}

Background: Globally, there are over 200 million cases of malaria annually and over 400,000 deaths. Early and accurate detection of low density parasitemia and asymptomatic individuals is key to achieving the WHO's 2030 sustainable development goals of reducing malaria-related

22 deaths by $90 \%$ and eradication in 35 countries. Current rapid diagnostic tests are neither sensitive

23 nor specific enough to detect the low parasite concentrations in the blood of some asymptomatic

24 individuals.

25 Methods: Here, we combine an imaging-based sensing technique, particle diffusometry (PD), 26 with loop mediated isothermal amplification (LAMP) on a smartphone-enabled device to detect

27 low levels of parasitemia often associated with asymptomatic malaria. After amplification, PD 28 quantifies the Brownian motion of fluorescent nanoparticles in the solution during a 30 second 29 video taken on the phone. The resulting diffusion coefficient is used to detect the presence of 30 Plasmodium DNA amplicons by comparing to coefficients of negative samples using a one-way 31 ANOVA test. 
32 Results: As few as 1 parasite/ $\mu \mathrm{L}$ of blood was detectable in 45 minutes without DNA

33 extraction. We detected Plasmodium falciparum (P. falciparum) parasites from asymptomatic

34 individuals' whole blood samples with $89 \%$ sensitivity and $100 \%$ specificity when compared to

35 quantitative polymerase chain reaction (qPCR).

36 Conclusions: PD-LAMP is of value for the detection of low density parasitemia especially in

37 areas where trained personnel may be scarce. The demonstration of this smartphone biosensor

38 paired with the sensitivity of LAMP provides a proof of concept to achieve widespread

39 asymptomatic malaria testing at the point of care.

\section{Background}

Malaria is a crucial public health concern in resource-constrained countries. In 2018,

$$
\text { there were } 228 \text { million cases of malaria and 405,000 malaria related deaths worldwide.(1) }
$$

Despite the World Health Organization's (WHO) strategic goal to eradicate malaria in 10

countries and reduce global incidence by $40 \%$ by 2020 , malaria cases have increased in the past several years.(2,3) Countries throughout sub-Saharan Africa carry the greatest percentage of malaria cases (92\%), followed by countries in Southeast Asia (5\%).(2) One contributing factor to the disproportionate number of malaria cases in sub-Saharan Africa is delayed or inaccurate results along with a lack of access to malarial diagnostic tools that are practical for field use.(4)

There is a need for portable, prompt, and easy-to-use diagnostic tools to decrease mortality from such a curable and preventable disease.(5)

Malaria is caused by the protozoan parasite Plasmodium with Plasmodium falciparum ( $P$. falciparum) being the deadliest in Africa. $(2,4)$ When $P$. falciparum malaria is left untreated it can become fatal and accounts for $99 \%$ of malaria deaths.(2) Malaria symptoms are nonspecific and often mimic symptoms of common viral and bacterial illnesses.(6) However, a large 
55 proportion of malaria cases are asymptomatic in endemic countries.(7-9) Asymptomatic carriers

56 of $P$. falciparum malaria are largely responsible for persistent transmission by maintaining the

57 parasite life cycle. $(8,10,11)$ Malaria management strategies are needed to control and monitor

58 infections in asymptomatic carriers and are a key step towards elimination.(10)

59 Rapid and sensitive asymptomatic malaria detection would provide real-time disease

60 surveillance for disease outbreak identification and prevent further transmission. However,

61 current on-site malaria detection approaches often rely on diagnostics that are not sensitive

62 enough for asymptomatic malaria cases. $(12,13)$ The standard method for diagnosing malaria is

63 through microscopic examination of blood smears. Microscopy achieves a sensitivity of 50-100

64 parasites/ $\mu$ L.(12,14-17) Major drawbacks of microscopy include the need for extensive technical

65 training for skilled personnel and the lack of quality control that is introduced in the diagnostic

66 interpretation.(12) An alternative approach, polymerase chain reaction (PCR), is by far the most

67 sensitive malaria diagnostic on the market with a limit of detection (LOD) of 5 parasites $/ \mu \mathrm{L}$, but

68 requires expensive equipment and reagents not found in local clinical facilities. $(18,19)$

69 Additionally, rapid diagnostic tests (RDTs) have been developed as a simple point-of-care

70 alternative for malaria diagnosis, which require little technical training and no laboratory

71 infrastructure.(20) However, common RDTs are currently not sensitive enough to accurately

72 detect below 100 parasites $/ \mu \mathrm{L}$ of blood, a concentration too high to identify malaria in some

73 asymptomatic individuals.(21-24)

Isothermal amplification methods eliminate the thermal cycling that is needed for highly

75 accurate methods such as PCR and have the ability to robustly amplify nucleic acids in complex

76 matrices while maintaining sensitivity and specificity. $(25,26)$ This simplifies the process and

77 decreases the time from sample to answer. $(25,26)$ The use of one such isothermal technique, 
78 loop mediated isothermal amplification (LAMP) is an attractive nucleic acid amplification

79 technique for field use due to its simplicity and robustness in complex matrices in comparison to

80 other isothermal methods.(27) LAMP-based assays have also been deemed appropriate for

81 detection of low-level parasitemia with the commercialized Loopamp ${ }^{\mathrm{TM}}$ malaria Pan/Pf kit by

82 having an excellent limit of detection of 2 parasites/ $\mu$ L. $(27,28)$ However, DNA still needs to be

83 extracted from the organism to use the Eiken kit. LAMP detection from blood without sample

84 purification has been done previously with 1000 fold dilution of the blood samples and blood

85 spots using chemical lysis through commercialized Loompamp kits $(29,30)$. However these

86 methods are commonly analyzed based on fluorescence detection adding to testing complexity

87 but can be expounded upon to increase its compatibility for field use.

LAMP is often monitored by turbidity, fluorescence, and electrochemical methods

89 (14,31,32). To accurately measure these signals, many research groups have begun to rely on the

90 use of smartphones as sensing instruments. Smartphones are the next leading technology in the

91 medical field as they are an attractive alternative to expensive medical equipment, oftentimes

92 contain a camera, GPS capabilities, and vibrational sensors that can be manipulated for

93 implementation of advanced diagnostics.(33) Smartphone-enabled LAMP-based diagnostics for

94 detection of Plasmodium has been performed previously and shows promise for assisted

95 microfluidic lab-on-a-chip devices. $(20,34)$ With developments on previous works, a feasible

96 point-of-care diagnostic can be developed to combat the challenges present in parasite detection

97 including laborious DNA extraction, purification and low-level malaria parasite detection in one 98 device.

99 An alternative highly sensitive detection method applying the optical sensing technique 100 is particle diffusometry paired with LAMP (PD-LAMP). PD-LAMP has previously been 
101 demonstrated by Clayton and Moehling et al., for the environmental detection of Vibrio

102 cholerae.(35) The presence of a pathogen is detected by measuring the Brownian motion of

103 particles in solution after LAMP. The LAMP assay, with biotinylated primers incorporated,

104 produces approximately $10^{9}$ copies of target DNA amplicons. These amplicons consist of stem-

105 loops with varying lengths; increasing the viscosity of the sample drastically (Figure 1A). $(16,36)$

106 These LAMP amplicons are then combined with $400 \mathrm{~nm}$ streptavidin-coated fluorescent particles

107 and placed into a microfluidic chip (Figure 1A). The fluorescent particles bind the biotinylated

108 DNA primer that is hybridized into the DNA amplicons resulting in an increase in the

109 hydrodynamic radius of the particles, further slowing their Brownian motion. Movement of the

110 fluorescent particles is captured in a series of images via the smart-phone camera. Correlation-

111 based algorithms of the images are used to calculate the diffusion coefficient of the particles

112 (Figure 1B). Combined, the particle size change and increased fluid viscosity yields a significant

113 difference between the diffusion coefficients of particles in positive versus negative samples.(35)

114 Diffusion coefficients are low in the presence of the targeted pathogen and in the absence of

115 pathogen nanoparticles will exhibit higher diffusivity. Clayton and Moehling et al. used PD-

116 LAMP to sensitively and specifically detect $10 \mathrm{~V}$. cholerae cells in a $25 \mu \mathrm{L}$ reaction in pond

117 water within 35 minutes.(35) However, this technique was performed using a laboratory

118 epifluorescence microscope, a method that is not easily accessible at the point of care. More

119 recently, Moehling and Lee et al. expanded upon the PD-LAMP method, achieving the same

120 limit of detection of $V$. cholerae cells in pond water using a newly developed smartphone-

121 enabled detection platform.(37) Their newly developed portable device miniaturizes a

122 fluorescent microscope and takes advantage of the smartphone camera and computational power

123 needed to perform PD-LAMP.(37) 


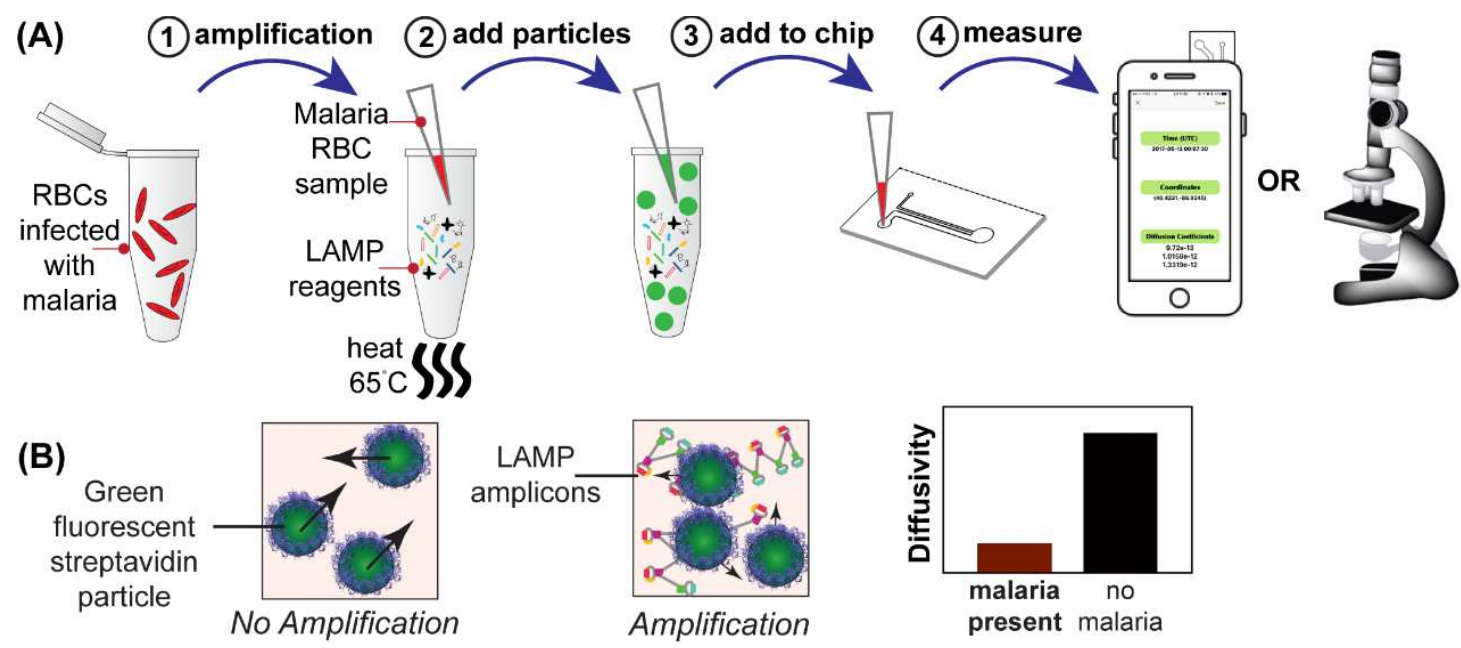

124

125

126

127

128

129

130

131

132

133

134

135

136

137

138

139

140

141

142

143

144

145

Figure 1. Illustration of PD-LAMP set-up. (A) LAMP was performed with whole blood samples added directly to the assay reagents. (A1) The red blood cells lysed upon heating, releasing the malaria DNA and initiating the LAMP reaction. (A2) After LAMP is completed, the amplicons are combined with fluorescent particles and (A3) the mixture was then added to a microfluidic chip. (A4) Imaging of the fluorescent beads took place using an epifluorescent microscope or the smartphone device (developed by Moehling and Lee et al.)(37) (B) The smartphone images the fluorescent particles undergoing Brownian motion for 30 seconds. The particles will exhibit faster Brownian motion in the absence of DNA amplicons. In the presence of malaria DNA, the particle motion will be hindered. The diffusion coefficient value, a numerical measure of Brownian motion, is lower when malaria DNA is amplified than if no malaria DNA is present. Here, we show the detection of low concentrations of Plasmodium parasites from unprocessed

blood using PD-LAMP. We used a previously published primer set targeting the 18s rRNA gene (38) that is specific to $P$. falciparum and $P$. vivax and further designed a novel 6-primer LAMP assay to amplify pan-Plasmodium by targetting the 28s rRNA gene which is conserved across all malaria species. We employ rapid, specific, and robust smartphone-enabled 5. Methods

\section{Loop Mediated Isothermal Amplification (LAMP)}

Purified genomic DNA from P. falciparum 3D7 (UK repository) was stored at $66 \mathrm{ng} / \mu \mathrm{L}$

$$
\left(3 \times 10^{6} \text { copies } / \mu \mathrm{L}\right) \text { at }-20^{\circ} \mathrm{C} \text {. The stock was diluted } 10 \text {-fold }\left(3 \times 10^{0}-10^{4} \text { copies/reaction }\right) \text { in }
$$

molecular biology water (Invitrogen, Carlsbad, CA) for experiments. The 28s rRNA LAMP

$$
\text { primers were designed using primer explorer to target the Plasmodium 28s rRNA, a gene }
$$

$$
\text { conserved across all Plasmodium species a gene conserved across } P \text {. vivax and } P \text {. falciparum. }
$$


146 18s rRNA, another conserved gene, primers used in this study were adopted from Lau et al.(38)

147 Primer sequences can be found in Table S1 and S2.

$148 \quad$ For all amplification experiments a master mix containing $22.5 \mu \mathrm{L}$ of master mix (master

149 mix recipe found in Table S3) and $2.5 \mu \mathrm{L}$ of template or NTC were added just prior to heating.

150 The templates were genomic DNA or infected blood; negative template controls (NTCs) were of

151 molecular biology water or uninfected blood, respectively. The reactions were heated at $65^{\circ} \mathrm{C}$ for

15245 minutes for all reactions without blood and all clinical samples with the 18 s primer set, 60

153 minutes for specificity reactions with blood, or 75 minutes for sensitivity reactions with blood

154 using an Applied Biosystems 7500 Real time PCR System (Foster City, CA). Samples were

155 stored at $4^{\circ} \mathrm{C}$ before $\mathrm{PD}$ analysis.

156 LAMP products were visualized using an ethidium bromide stained $2 \%$ agarose gel at

$157100 \mathrm{~V}$ for 50 minutes. The gel was imaged using an ultraviolet light gel system (c400, Azure

158 Biosystems, Dublin, CA). Gel images were collected with an exposure time of 15 seconds using

159 the Azure cSeries software at settings of UV302. Gel images were transferred from the Azure as

160 .tiff files and have not been cropped or edited in this manuscript.

\section{PD-LAMP Particle Preparation and Imaging}

162 For PD measurements, $400 \mathrm{~nm}$ streptavidin coated Dragon Green polystyrene beads (Bangs

163 Laboratories, Fishers, IN) were added to the LAMP samples at a final concentration of $6 \times 10^{9}$

164 particles/mL. After 10 seconds of microcentrifugation $3 \mu \mathrm{L}$ of the LAMP and bead sample was

165 placed into the microfluidic chip imaging chamber. Each sample was imaged for 30 seconds in

166 the smartphone-enabled platform twice and analyzed using an in-house algorithm.(37) The

167 diffusion coefficients were exported for statistical analysis. 
For the microscope images, the samples $(\mathrm{N}=3)$ were imaged for 1000 frames using an

169 inverted fluorescence microscope (Carl Zeiss Microscopy, Thornwood, NY).(35) A 40x

170 magnification objective lens was used with the ZEN software and Zeiss camera at 13.5 frames

171 per second. Each sample video from the microscope was analyzed using an in-house MATLAB

172 code to obtain diffusion coefficients.

\section{Chip Preparation}

174 The microfluidic chip for phone measurements was manufactured by pressure and heat with a

175 heat press (Carver Inc. Wabash, IN). The chip consisted of two $188 \mu \mathrm{m}$ thick cyclic olefin

176 polymer (COP) sheets (Zeon, Tokyo, Japan) that were adhered together at 1.2 metric tons at

$177120^{\circ} \mathrm{C}$ for 2 minutes and then rotating the COP sheets $180^{\circ}$ and pressing for another 1 minute.

178 Double-sided sticky tape (120 $\mu \mathrm{m}$ thickness iCraft Super Tape) had a 1/8" (3mm) through-hole

179 fabricated with a hole punch. The tape was placed on one side of the pressed $188 \mu \mathrm{m}$ sheets. The

180 tape acted as the fluid sample well. A $60 \mu \mathrm{m}$ COP sheet was placed on top of the double-sided

181 sticky tape after adding the sample to prevent evaporation.

182 For the samples analyzed via microscope, $6 \mathrm{~mm}$ punches were used on double-sided

183 sticky tape to act as a sample well. The tape was placed onto a cover glass slide (Thickness No.

184 1, Thermo Scientific, Erie, NY, USA) $3 \mu \mathrm{L}$ sample was placed into the wells and sealed with a

185 second cover glass slide to limit evaporation.(35)

186 Theory of Particle Diffusometry

187 PD-LAMP is a correlation-based fluid visualization technique that utilizes imaging of Brownian

188 motion of particles post-DNA amplification.(51-53) Diffusion coefficients are calculated by

189 correlating sequential particle images and using autocorrelation and cross-correlation of these

190 images to measure particle pixel displacement. The greater particle displacement between images 
191 creates a broader cross-correlation peak width, $s_{c}$. The autocorrelation coefficient $s_{a}$ is

192 determined by correlating an image captured at time $t$ with itself. Through the use of these

193 correlation coefficients the diffusion coefficient can be calculated by an equation derived by

194 Olsen and Adrian:(54)

195

$196 \quad D=\frac{s_{c}^{2}-s_{a}^{2}}{16 M^{2} \Delta t}$

198 where $\mathrm{M}$ is the magnification of the microscope objective. $\mathrm{D}$ is the diffusion coefficient where its 199 theoretical value is calculated using the Stokes-Einstein equation $(55,56)$.

$200 \quad D=\frac{k T}{6 \pi \eta a}$

201 Here $\mathrm{k}$ is the Boltzmann constant, $\mathrm{T}$ is the absolute temperature, $\eta$ is the viscosity and a is the

202 hydrodynamic radius of the imaged fluorescent particles. The equations 1 and equation 2 and

203 its use in PD-LAMP have been previously described $(35,37,52)$.

204

205 Patient/Study Participant Samples and Malarial DNA

206 Genomic P. falciparum 3D7A DNA was obtained from the European Malaria Reagent

207 Repository. NIAID, NIH: Plasmodium falciparum, Strain 3D7, MRA-102, contributed by Daniel

208 J. Carucci, and NIAID, NIH: Plasmodium vivax, Strain Chesson, MRA-383, contributed by W.

209 E. Collins, were obtained through BEI Resources. Human blood (Innovative Research Novi, MI)

210 was used to dilute infected blood samples.

211 Cerebral malaria (CM), severe malarial anemia (SMA), and community control (CC)

212 blood samples were collected as part of a study conducted at Mulago National Referral Hospital

213 in Kampala, Uganda from 2008-2013 as previously described.(39) Children 18 months to 12 
214 years of age were enrolled into the CM group if they had coma (Blantyre Coma Score $\leq 2), P$.

215 falciparum on blood smear, and no other known cause of coma (e.g. meningitis, a prolonged

216 postictal state, or hypoglycemia-associated coma reversed by a glucose infusion) or into the

217 SMA group if they had $P$. falciparum on blood smear and serum $\mathrm{Hgb} \leq 5 \mathrm{mg} / \mathrm{dL}$. CC were

218 healthy children in the same age group and from the same neighborhood, extended household, or

219 nearby neighborhood as a child with CM. Whole blood was also obtained from a Kenyan

220 individual with uncomplicated malaria (UM) and from North American individuals without

221 malaria (IRB protocol 1601403732). DNA was extracted from whole blood samples using the

222 QIAamp DNA Blood Mini Kits (Qiagen, Hilden, Germany) for nPCR and qPCR testing.

223 Blinded Study

224 P. falciparum positive or negative patient samples $(2.5 \mu \mathrm{L})$ were placed into a PCR strip tube

225 labeled 1-7. The master mix was prepared, and the samples added. Samples were heated to $65^{\circ} \mathrm{C}$

226 for 45 minutes for the 18 s primer set and 90 minutes for the $28 \mathrm{~s}$ primer set. The researchers

227 performing amplification and PD experiments were blinded to the parasitemia sample

228 concentration. After PD-LAMP was performed, the diffusion coefficients were then matched

229 with the initial concentrations to obtain unbiased measurements.

230 Nested Polymerase Chain Reaction

231 nPCR was used to first amplify the genus specific 18 s ribosomal RNA common to all

232 Plasmodium species using the rPLU1 and rPLU5 primers as described in the Snounou

233 protocol(57) and the cycling method as described in the Bharti protocol.(58) Then, the product of

234 this first reaction was used as the DNA template for the second, $P$. falciparum species-specific

235 amplification using the rFAL1 and rFAL2 primers as described in the Snounou protocol with the

236 same cycling conditions as the first amplification. 


\section{Quantitative Polymerase Chain Reaction}

238 qPCR targeting the multi-copy nuclear varATS gene was performed on the study participant

239 samples that also underwent PD-LAMP. $20 \mu \mathrm{L}$ reactions were run on the Applied Biosystems ${ }^{\mathrm{TM}}$

240 QuantStudio ${ }^{\text {TM }} 6$ Flex Real-Time PCR System (Foster, CA) using primers and protocol

241 previously described(59) but modified for PowerUp ${ }^{\text {TM }}$ SYBR ${ }^{\mathrm{TM}}$ Green Master Mix (Applied

242 Biosystems, Foster, CA) (Table S4). Parasite density was quantified by comparison to a standard

243 curve of 3D7 parasite cultures. After 2 rounds of synchronization (5\% sorbitol), parasite

244 concentration was determined using the parasitemia calculation described below and the RBC

245 concentration via hemocytometer. A 10-fold serial dilution of parasite culture in RPMI diluted in

246 malaria-negative O+ blood was produced and the DNA isolated using the QIAamp DNA Blood

247 Mini Kits (Qiagen, Hilden, Germany) to create the standards ( 1 x $10^{5}-1 \times 10^{-1}$ parasites $\left./ \mu \mathrm{L}\right)$. All

248 standards, controls, and samples were quantified in duplicate and averaged.

\section{Parasitemia and Parasite Density Calculations}

250 Parasitemia of the NIAID, NIH: P. falciparum, Strain 3D7, MRA-102 and NIH: Plasmodium

251 vivax, Strain Chesson, MRA-383 containing live parasites, were verified by microscopy.

252 Microscopy was performed on a sample of $1.5 \mu \mathrm{L}$, of the P.f. or P.v. sample, using a thin blood

253 smear to determine \% parasitemia and then converted to parasite concentration. The smear was

254 fixed onto a glass slide using methanol and stained with Wright-Giemsa stain for 15 minutes.

255 Parasites were visualized and counted using a 100x oil immersion objective under white light. At

256 least 500 RBC's were counted to determine \% parasitemia. The equation 3 shows the

257 calculation for estimating parasite concentration from the blood smear using an estimated

258 average red cell count of 5,000,000 RBC's per $\mu L$. 


$$
\text { parasites } / \mu L=\frac{\# \text { of parasites }}{\# \text { of } R B C^{\prime} s} \times 5,000,000
$$

260 Parasite densities for clinical samples were calculated based on the number of asexual parasites 261 per $\mu \mathrm{L}$ of blood on a thick smear stained with $10 \%$ Giemsa. Parasites were counted until the field

262 containing the $200^{\text {th }}$ white blood cell (WBC) was reached. Then, density was calculated based on 263 the study participant's WBC count as described by equation 4 below.

$$
\frac{\# \text { of parasites } \times W B C \text { count }}{\# \text { of } W B C \text { counted }}=\# \text { of parasites per } \mu l \text { of blood }
$$

\section{Statistical Analysis}

266 Statistical tests were used for data analysis of all specificity and sensitivity measurements. The

267 LOD was determined from PD data by using a one-way ANOVA post-hoc Dunnett's compared

268 to the negative controls (NTC) with a 95\% confidence interval. Box-and-whisker plots were

269 made for PD measurements at the 10-fold dilutions where the minimum and maximum values

270 were represented by the upper and lower whiskers. Quartiles $25 \%$ and $75 \%$ were represented by

271 the upper and lower bounds respectively.

272 PD-LAMP for the detection of asymptomatic malaria in a portable detection platform.

\section{Results}

\section{PD-LAMP Comparison in Phone and Microscope}

275 LAMP reactions targeting the 28s rRNA gene were performed across 10-fold serial

276 dilutions from $3 \times 10^{4}$ to $3 \times 10^{0}$ DNA copies/ $\mu$ L of $P$. falciparum DNA. All dilutions amplified in

277 less than 45 minutes as visualized by the sigmoidal increase in real-time fluorescence

278 measurements (Figure 2A). Real-time fluorescence visualization shows that the highest initial

279 concentrations of 28s RNA amplified more rapidly. Negative template control (NTC) samples

280 remained at baseline throughout the 45-minute amplification for all instances in the qPCR graphs 
$281(\mathrm{~N}=4)$ (Figure $\mathrm{S} 1)$. Amplification was confirmed with a 2\% agarose gel showing banding only in 282 positive samples (Figure 2B).

283 We used the 28s rRNA LAMP products to validate the PD measurements made on an 284 inverted epifluorescent microscope against PD measurements on the smartphone device with an 285 in-house MATLAB code. After performing a one-way ANOVA with Dunnett's post-hoc against 286 the NTC, we found that there were statistically significant differences between sample dilutions $2873 \times 10^{4}-3 \times 10^{1}(* * * * \mathrm{p}<0.0001)$ and $3 \times 10^{0}(* \mathrm{p}<0.05)$ DNA copies/ $\mu \mathrm{L}$ relative to the NTC for both 288 PD measurements on the microscope (Figure 2C) and the smartphone device (Figure 2D). PD 289 yielded lower diffusion coefficients in positive samples as expected due to the inhibition of 290 particle Brownian motion in the presence of malaria DNA amplicons. To ensure reproducibility 291 each sample was measured in duplicate on each platform after 4 different amplification 292 experiments $(\mathrm{N}=4)$. We determined that there were no significant differences in the 293 measurement efficacy between the microscope and smartphone platform. 
(A)

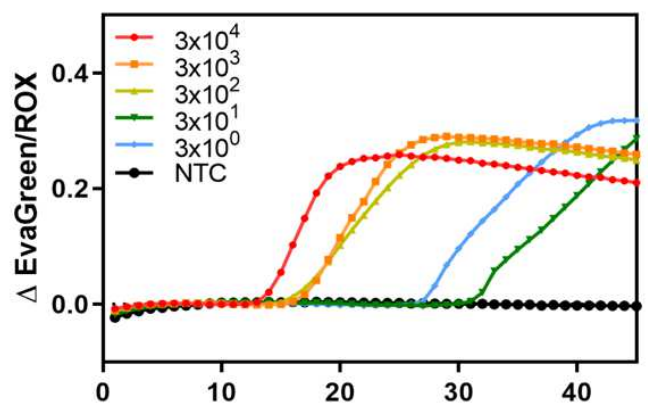

(C)

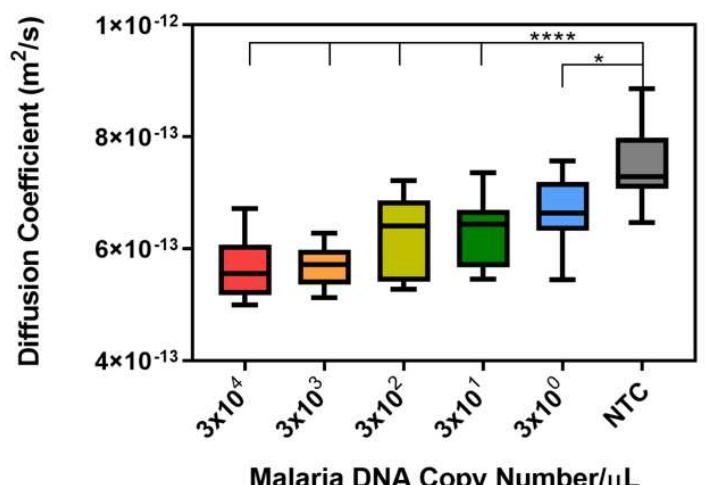

Malaria DNA Copy Number/ $\mu \mathrm{L}$

Microscope Data
(B)

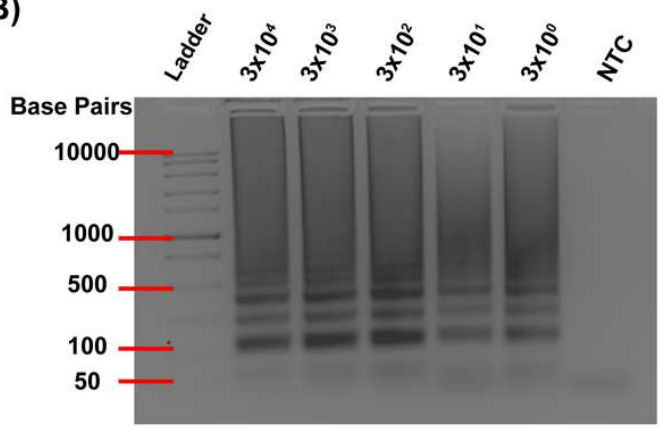

(D)

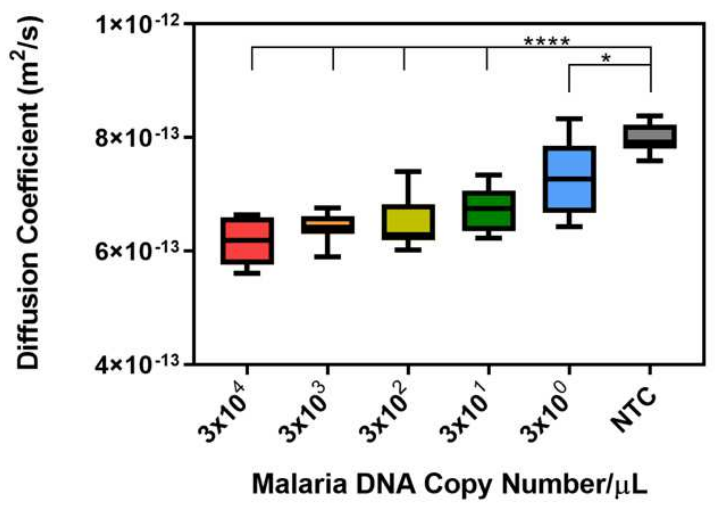

Phone Data

Figure 2. P. falciparum genomic DNA detection targeting $28 \mathrm{~s}$ rRNA. (A) Real-time fluorescence data during a 45 -minute LAMP reaction with concentrations ranging from $3 \times 10^{4}$ to $3 \times 10^{0} \mathrm{DNA}$ copies/ $\mu \mathrm{L}$. (B) The representative LAMP DNA banding pattern for all positive samples are confirmed in $2 \%$ agarose gel electrophoresis (note the NTC shows no banding pattern). (C) PD analysis from the microscope images of the samples indicates the change in diffusion coefficient for LAMP samples with a statistically significant difference from the negative template control (NTC) for samples with $3 \times 10^{4}-3 \times 10^{1}(* * * * p<0.0001)$ and $3 \times 10^{0}(* \mathrm{p}<0.05)$ DNA copies $/ \mu \mathrm{L}$. (D) $\mathrm{PD}$ analysis on smartphone device indicates statistically significant differences between $3 \times 10^{4}$ $3 \times 10^{1}(* * * * p<0.0001)$ and $3 \times 10^{0}(* \mathrm{p}<0.05)$ DNA copies $/ \mu \mathrm{L}$ and the NTC. NTC here represents water added in place of genomic DNA. $(\mathrm{N}=4)$

\section{8s rRNA PD-LAMP Specificity in Blood}

As Plasmodium parasites reside in red blood cells, we needed to assess the feasibility of

PD-LAMP in whole blood samples. We performed LAMP with $P$. falciparum genomic DNA at a concentration of $10^{4}$ copies $/ \mu \mathrm{L}$ in reactions containing several whole blood concentrations (v/v).

The amplification time was extended from 45 to 60 minutes due to the inhibition caused by the

311 addition of blood. Samples containing P. falciparum genomic DNA amplified when up to 10\% 
312 of the reaction volume consisted of blood (Figure S2). No amplification occurred in $15 \%$ blood

313 or greater. Further, no non-specific amplification occurred with the NTC in the reactions

314 consisting of $10 \%$ blood (Figure S3). Therefore, $10 \%$ blood was the greatest concentration that

315 could be used without inhibiting LAMP or causing non-specific amplification of control

316 samples.

317 To ensure assay selectivity for malaria, LAMP targeting 28s rRNA was performed with

318 with P. falciparum and P. vivax blood samples (BEI), alongside dengue virus (III) and

319 chikungunya virus RNA, which are also mosquito-borne pathogens, but do not contain the 28s

320 rRNA gene. We performed a 60-minute LAMP assay for each sample in a reaction containing

$321 \quad 10 \%$ blood. Specific amplification occured for the $P$. falciparum and $P$. vivax DNA samples

322 while dengue virus (III) and chikungunya virus did not amplify, as indicated on an agarose gel

323 (Figure 3A). Following amplification, we performed PD on the LAMP samples. Dunnett's post-

324 hoc test was used against each individual sample. We saw no significant change in the PD signal

325 against NTC (p > 0.5) in the presence of dengue virus (III) or chikungunya virus $\mathrm{RNA}(\mathrm{N}=4)$

326 (Figure 3B). Alternatively, both malaria positive samples (P. falciparum and $P$. vivax) were

327 found to be significantly different from dengue and chikungunya virus samples and the NTC

328 (unifected blood) $(* * * * p<0.0001)$, but not from each other. 


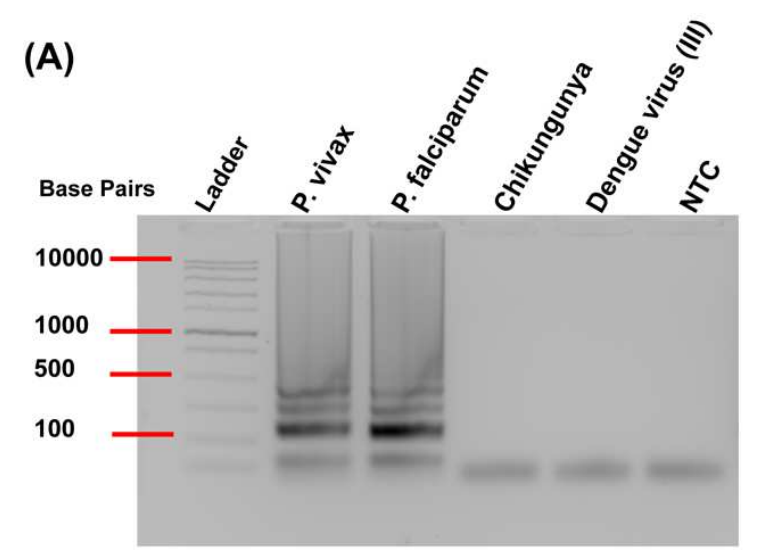

(B)

Figure 3. PD-LAMP specificity in $10 \%$ blood. (A) A $2 \%$ agarose gel from LAMP reactions in

PD-LAMP Sensitivity in $10 \%$ Blood (v/v) with Infected RBCs

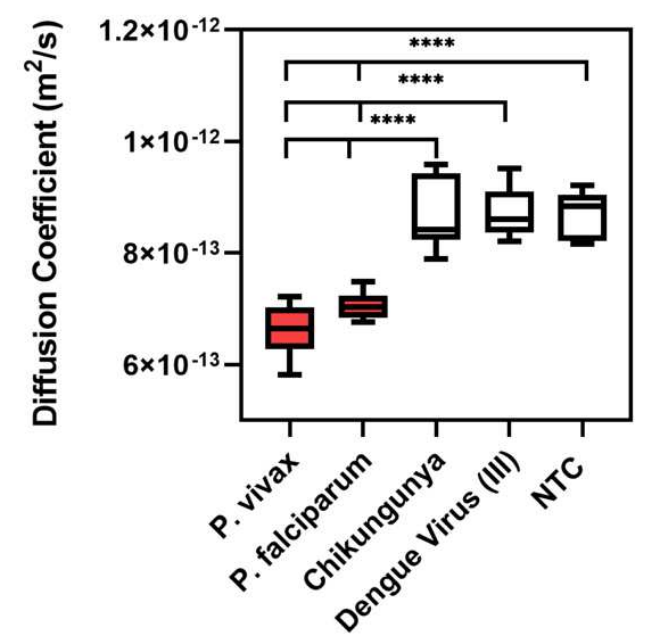
blood containing malarial strains $P$. falciparum and $P$. vivax alongside controls chikungunya and dengue virus (III) at $6 \times 10^{4}$ parasites $/ \mu \mathrm{L}$ blood after a 60 -minute LAMP reaction. Only malaria samples amplified, demonstrated by the DNA banding pattern in the gel. (B) Diffusion coefficients from smartphone PD analysis, where malaria samples showed a significant difference from chikungunya virus, dengue virus (III) and NTC (One-way ANOVA Dunnett's post-hoc test). NTC represents blood without spiked pathogens. $(\mathrm{N}=3)$

340 malaria infected blood samples. The stock infected blood was diluted with uninfected blood to

341 obtain 10 -fold dilutions between $3 \times 10^{5}$ to $3 \times 10^{0}$ parasites $/ \mu \mathrm{L}$ of blood for a 75 -minute LAMP

342 reaction using 28s rRNA primers. From the LAMP assay, we determined that the LOD was 3 
343 parasites $/ \mu \mathrm{L}$. Amplification was confirmed with a $2 \%$ agarose gel (Figure 4A). Further, when

344 measured by PD-LAMP, amplification from as few as 3 parasites/ $\mu \mathrm{L}$ blood resulted in a

345 significantly reduced diffusion coefficient compared to NTC in blood (N=4) (Figure 4B).

346 Dunnett's post-hoc test for all samples confirmed significance from NTC with ****p<0.0001

347 for $3 \times 10^{5}$ to $3 \times 10^{2}$ and $* * \mathrm{p}<0.001$ for $3 \times 10^{1}$ to $3 \times 10^{0}$.

(A)

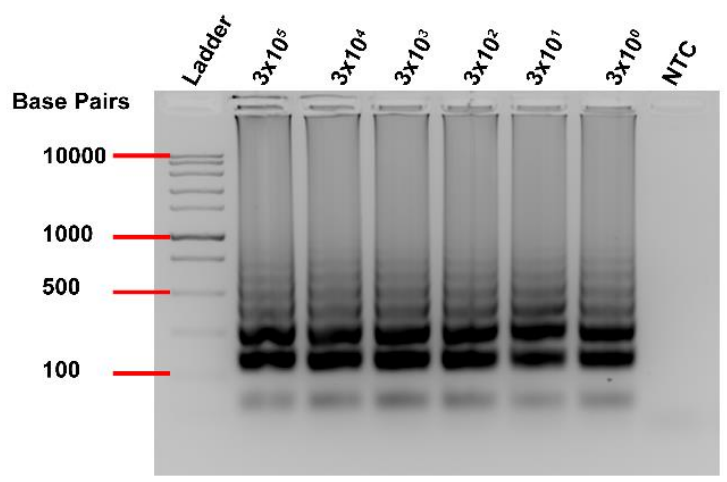

(B)

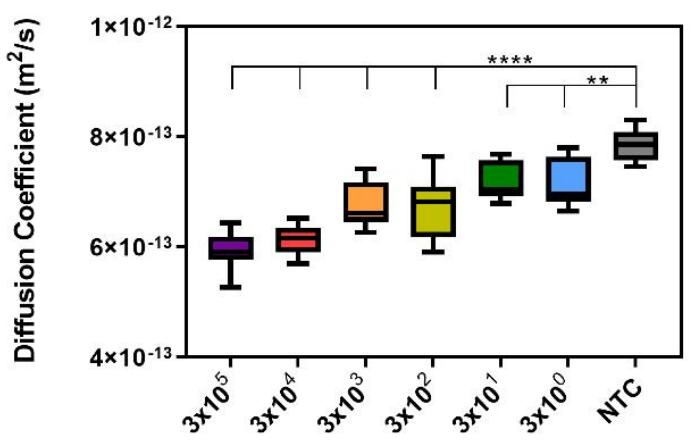

Parasites/ $\mu$ L Blood
348

Figure 4. Sensitivity of malaria PD-LAMP with 28 s primers using $10 \%$ blood. (A) $2 \%$ agarose gel confirming amplification in positive samples. (B) Diffusion coefficients measured using smartphone device for dilutions of $3 \times 10^{5}-3 \times 10^{0}$ of P. falciparum infected blood after a 75 -minute reaction. $\mathrm{PD}$ analysis shows statistical difference from controls for $3 \times 10^{5}-3 \times 10^{2}$ parasites $/ \mu \mathrm{L}$ blood $(* * * \mathrm{p}<0.0001)$ and $3 \times 10^{1}-3 \times 10^{0}$ parasites $/ \mu$ L blood $(* * \mathrm{p}<0.001) .(\mathrm{N}=4)$.

\subsection{Blinded Study of PD-LAMP in Infected Blood Samples with PCR Confirmation}

We performed a blinded study with patient blood samples to validate the robustness of the smartphone device. Six previously collected and deidentified malaria samples (labeled patient ID 1-6) with parasite densities ranging from 4 parasites $/ \mu \mathrm{L}$ to 265,782 parasites $/ \mu \mathrm{L}$ as quantified by qPCR were used for this study.(39) Each sample was analyzed on the smartphone via PD-LAMP in a blinded study where the user of the device did not know the nature of the samples being analyzed. The samples were amplified using two different primer sets, $28 \mathrm{~s}$ rRNA and $18 \mathrm{~s}$ rRNA. The 18s rRNA primer set was introduced to this work to reduce the amplification 
363 time of the patient samples because there are more copies of the 18s rRNA gene than 28s rRNA

364 in the P. falciparum genome.(40) Table 1 shows quantitative PCR (qPCR) values, microscopy,

365 and diffusion coefficients (PD-LAMP) for each sample using the 18s and 28s rRNA primers.

366 The 18s rRNA PD-LAMP resulted in diffusion coefficients of less than $7.2 \mathrm{e}^{-13} \mathrm{~m}^{2} / \mathrm{s}$ for all

367 patients with parasitemia while the NTC resulted in a diffusion coefficient of $9.0 \mathrm{e}^{-13} \mathrm{~m}^{2} / \mathrm{s}$, higher 368 than the positive samples.

369 From the LAMP assay, all 6 patient samples that incorporated primers targeting the $18 \mathrm{~s}$

370 rRNA gene amplified within 45 minutes. Samples with the 28s rRNA primer set underwent a 90-

371 minute reaction and two of the patient samples did not amplify. Agarose gel electrophoresis

372 confirmed LAMP amplification of all positive samples at the end of the blinded study using the

373 18s primer set $(\mathrm{N}=3)$ (Figure S5A). Measuring the LAMP products with $\mathrm{PD}$, we found all of the

374 diffusion coefficient values for patient samples to be significantly different from NTC for $18 \mathrm{~s}$

375 rRNA gene target $(* * * * p<0.0001)$ (Figure S5B). For patient samples targeting the 28 s rRNA

376 gene, we observed that Patient ID 3 and 4 both showed inconsistent amplification in the agarose

377 gels while all other patient samples indicate consistent amplification between repeats $(\mathrm{N}=3)$

378 (Figure S5C). Targeting the 28s rRNA gene, patient ID 3 and 4 were not found to be

379 significantly different from NTC after a 90-minute amplification. All other patient samples with

380 LAMP targeting the 28s rRNA gene were found to be significant from PD measurements

$381 \quad(* * * * \mathrm{p}<0.0001$ for 1 and $5, * * * \mathrm{p}<0.001$ for $2, * * \mathrm{p}<0.01$ for 6$)$ (Figure S5D). The nature of this

382 blinded study showed reproducibility in using PD for the detection of LAMP amplicons in the

383 smartphone device as well as the importance of choosing a robust LAMP assay target. 
Table 1. Parasite densities and average diffusion coefficients from 18s and 28s rRNA primers of patient samples. Quantitative PCR and PD-LAMP was performed on 6 infected blood samples and a negative control (uninfected blood). A significant difference $(\mathrm{p}<0.05)$ was shown in the diffusion coefficients of all positive samples compared to the control for 18s rRNA primers. A significant difference $(\mathrm{p}<0.05)$ was shown in the diffusion coefficients from controls for all samples except IDs 3 and 4 for 28s rRNA primers.

\begin{tabular}{|c|c|c|c|c|c|}
\hline $\begin{array}{l}\text { Patient } \\
\text { ID }\end{array}$ & Group & $\begin{array}{c}\text { Parasite } \\
\text { Density by } \\
\text { Microscopy } \\
\text { (parasites/ } \mu \mathrm{L} \text { ) }\end{array}$ & $\begin{array}{c}\text { Parasite } \\
\text { Density by } \\
\text { qPCR } \\
\text { (parasites/ } \mu \mathrm{L} \text { ) }\end{array}$ & $\begin{array}{l}\text { 28s Diffusion Coeff. } \\
( \pm \text { standard dev. }) \\
\underset{\left(\mathbf{m}^{2} / \mathbf{s}\right)}{ }\end{array}$ & $\begin{array}{l}\text { 18s Diffusion Coeff. } \\
( \pm \text { standard dev. }) \\
\quad\left(\mathbf{m}^{2} / \mathbf{s}\right)\end{array}$ \\
\hline 1 & $\mathrm{UM}^{\mathrm{a}}$ & N.D. ${ }^{\mathrm{e}}$ & 265,782 & $6.4( \pm 0.51) \mathrm{e}^{-13}$ & $6.1( \pm 0.61) \mathrm{e}^{-13}$ \\
\hline 2 & $\mathrm{CM}^{\mathrm{b}}$ & 64 & 126 & $6.7( \pm 1.31) \mathrm{e}^{-13}$ & $7.0( \pm 0.58) \mathrm{e}^{-13}$ \\
\hline 3 & $\mathrm{SMA}^{\mathrm{c}}$ & $524^{\mathrm{d}}$ & 4 & $7.9( \pm 0.91) \mathrm{e}^{-13}$ & $6.9( \pm 0.78) \mathrm{e}^{-13}$ \\
\hline 4 & $\mathrm{CM}$ & 545 & 2,552 & $7.7( \pm 0.67) \mathrm{e}^{-13}$ & $6.9( \pm 0.28) \mathrm{e}^{-13}$ \\
\hline 5 & $\mathrm{CM}$ & 26,643 & 1,466 & $6.5( \pm 0.51) \mathrm{e}^{-13}$ & $7.1( \pm 0.45) \mathrm{e}^{-13}$ \\
\hline 6 & $\mathrm{CM}$ & 511,972 & N.D. & $7.05( \pm 0.25) \mathrm{e}^{-13}$ & $6.9( \pm 0.35) \mathrm{e}^{-13}$ \\
\hline NTC & -- & 0 & - & $8.8( \pm 0.73) \mathrm{e}^{-13}$ & $9.0( \pm 1.01) \mathrm{e}^{-13}$ \\
\hline
\end{tabular}

${ }^{\mathrm{a}}$ Uncomplicated Malaria; ${ }^{\mathrm{b}}$ Cerebral Malaria; ${ }^{\mathrm{c}}$ Severe Malaria Anemia;

d parasite density not corrected for white blood cell count

enot determined

\section{LOD from Diluted Patient Samples}

We determined the LOD of PD-LAMP on the smartphone device using patient samples.

392 We performed 10-fold serial dilutions of patient sample ID 2, the $2^{\text {nd }}$ lowest concentration by 393 qPCR, in blood starting with a dilution from stock of 12.6 parasites $/ \mu \mathrm{L}$ to 0.0126 parasites $/ \mu \mathrm{L}$ and 394 performed PD after a 45-minute LAMP reaction using the 18s rRNA primer set. As shown in 395 Figure S5, the 18s rRNA primer set had greater reproducibility and amplified in less time than the 396 28s rRNA primer set. Therefore, 18s rRNA primer sets were chosen for this sensitivity study. The $3972 \%$ agarose gel indicated inconsistent amplification between repeats below 12.6 parasites $/ \mu \mathrm{L}$ 398 (Figure 5A). However, the LOD of PD-LAMP on the smartphone device was found to be 6 399 parasites $/ \mu \mathrm{L}$ (Figure 5B). The diffusion coefficient values were significantly different from NTC 400 for $12.6(* * * * \mathrm{p}<0.0001), 1.26$ and $0.126(* \mathrm{p}<0.05)$ parasites $/ \mu \mathrm{L}$ blood using one-way ANOVA 
post-hoc Dunnett's test. The lowest concentration, 0.0126 parasites $/ \mu \mathrm{L}$ blood, was not

402 significantly different from NTC (uninfected blood) but followed the same trend of having lower

403 diffusivity than the NTC. Thus, PD-LAMP is sensitive enough to detect amplicons even when they

404 cannot be ascertained via agarose gel electrophoresis and a LOD of 0.126 parasites/ $\mu \mathrm{L}$ was 405 obtained with the smartphone device from patient samples.

(A)

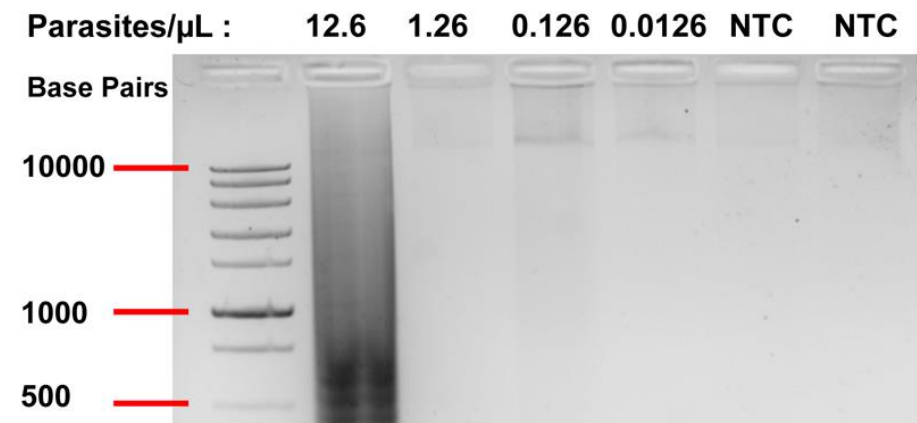

(B)

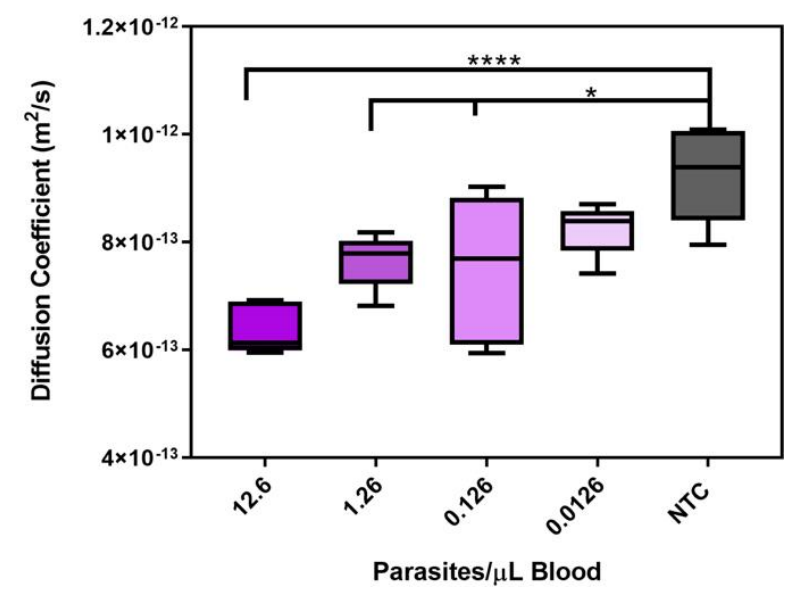

Figure 5. Serial dilutions of patient ID 2 for the determination of the LOD in patient samples using 18s primers. (A) A representative gel from dilutions of ID 2 with concentrations ranging from 12.6 to 0.0126 parasites $/ \mu \mathrm{L}$. Only the 12.6 parasites/ $\mu \mathrm{L}$ sample showed consistent amplification in gel represented by the dark smeared banding. (B) Diffusion coefficients from smartphone PD analysis of diluted samples yielded a LOD of 0.126 parasites/ $\mu \mathrm{L}$ blood. All dilutions, 12.6 parasites $/ \mu \mathrm{L}$ blood $(* * * * p<0.0001), 1.26$ and 0.126 parasites $/ \mu \mathrm{L}$ blood $(* \mathrm{p}<0.05)$, except 0.0126 parasites $\mu \mathrm{L}$ blood were found to be statistically different from NTC. $(\mathrm{N}=3)$

\section{PD-LAMP from Asymptomatic Samples}

We then determined if PD-LAMP could accurately detect $P$. falciparum in asymptomatic study participants. Whole blood samples were collected from 11 healthy asymptomatic individuals (community controls, CC) and 2 symptomatic individuals (Cerebral Malaria, CM and Severe Malaria Anemia, SMA) from Uganda and analyzed via microscopy on site and were stored for nested PCR (nPCR), qPCR, and PD-LAMP testing. Samples were tested in duplicate for qPCR assays targeting varATS gene, and for PD-LAMP assays using the 18s rRNA gene 
422 (N=4) (Table 2). For qPCR, the sample was deemed negative if all replicates were negative.

423 Each sample was also run on an agarose gel after a 45-minute LAMP reaction. We found 6 of the

42411 asymptomatic samples to be positive for P. falciparum via PD-LAMP using Dunnett's

425 multiple comparison test to healthy parasite-free controls, the same was true for the 2 out of 2

426 symptomatic individuals. PD-LAMP positive results correlated with $8 / 9$ of the positive results by

427 qPCR. Therefore, PD-LAMP was $89 \%$ sensitive and $100 \%$ specific when compared to qPCR

428 (Table 2). The nPCR, targeting 18s rRNA gene, detected 2 more positive cases than PD-LAMP

429 or qPCR (Table 2). This discordinance among molecular methods has been documented in

430 samples with very low levels of parasitemia.(41-43)

431 Table 2. Presence of $P$. falciparum parasitemia as asssessed by nested PCR (nPCR), quantitative 432 PCR (qPCR) and particle diffusion-LAMP (PD-LAMP) in community children with 433 asymptomatic parasitemia (CC), and positive control children with cerebral malaria (CM) or 434 severe malarial anemia (SMA)

\begin{tabular}{|c|c|c|c|c|}
\hline Study ID & Group & $\begin{array}{c}\text { Parasite Presence } \\
\text { (nPCR) }\end{array}$ & $\begin{array}{c}\text { Parasite Density } \\
\text { by qPCR } \\
\text { (parasites/ } \mu \mathrm{L} \text { ) }\end{array}$ & PD-LAMP \\
\hline 7 & $\mathrm{CC}^{\mathrm{a}}$ & - & 0 & - \\
\hline 8 & $\mathrm{CC}$ & - & 1 & + \\
\hline 9 & $\mathrm{CC}$ & - & 0 & - \\
\hline 10 & $\mathrm{CC}$ & + & 0 & - \\
\hline 11 & $\mathrm{CC}$ & + & 0 & - \\
\hline 12 & $\mathrm{CC}$ & + & 1 & - \\
\hline 13 & $\mathrm{CC}$ & + & 56 & + \\
\hline 14 & $\mathrm{CC}$ & + & 35 & + \\
\hline 15 & $\mathrm{CC}$ & + & 12,749 & + \\
\hline 16 & $\mathrm{CC}$ & + & 8.741 & + \\
\hline 17 & $\mathrm{CC}$ & + & 100,669 & + \\
\hline 18 & $\mathrm{CM}^{\mathrm{b}}$ & N.D. ${ }^{e}$ & 377,406 & + \\
\hline 19 & $\mathrm{SMA}^{\mathrm{c}}$ & N.D. & 136,926 & + \\
\hline
\end{tabular}


${ }^{\mathrm{a} C}$ Community Controls; ${ }^{\mathrm{b}}$ Cerebral Malaria; ${ }^{\mathrm{c}}$ Severe Malaria Anemia; ${ }^{\mathrm{e}}$ not determined

$-=$ negative for $P$. falciparum DNA, $+=$ positive for $P$. falciparum DNA

435

436

437

438

439

440

441

442

443

444

445

446

447

448

449

450

451

452

453

454

455

\section{Discussion}

Many low and middle income countries (LMICs) struggle to maintain laboratoryintensive testing programs that are necessary for accurate malaria diagnoses.(4) However, widescale testing for asymptomatic malaria infections will be a necessary component of WHO malaria reduction and elimination efforts. (44) In this work, we demonstrated the use of PD-

LAMP on a portable smartphone-enabled platform for the sensitive, rapid, and robust detection of malaria parasites from unfiltered blood. Through the use of genomic $P$. falciparum DNA, we were able to validate malaria detection on the smartphone first by comparing its results to PD measurements from a fluorescent microscope. Following this, we determined that the PD-LAMP smartphone platform has a LOD of 3 parasites/ $\mu \mathrm{L}$ (Figure 2) which is comparable to qPCR and Loopamp ${ }^{\mathrm{TM}}$ detection limits. ${ }^{[34]}$ Detection at this low concentration is promising for identifying asymptomatic cases that cannot be identified via microscopy. We have demonstrated that PDLAMP detects as few as 3 parasites $/ \mu \mathrm{L}$ in $10 \%$ whole blood and is 66 -fold more sensitive than currently used RDTs and comparable to the LAMP kit without sample purification.(23) Further, the PD-LAMP smartphone detection technique is 6-fold more sensitive than even emerging ultrasensitive RDTs, which detect down to 20 parasites/ $\mu \mathrm{L} .(21,46)$ By directly adding blood to the LAMP reaction, we have eliminated the need for DNA extraction and preprocessing steps (Figure 4). In the future, we foresee that the PD-LAMP smartphone device could be used for point-of-care malaria testing.

We confirmed the selectivity of the pan-Plasmodium 28s rRNA LAMP reaction to malaria by testing against chikungunya virus and dengue virus (III) RNA, spiked into blood. 
456 These viruses are also mosquito-borne and may have similar symptoms as malaria.(47) There are

457 also some regions where there are coinfections of dengue or chikungunya with malaria.(47)

458 Specifically identifying the Plasmodium parasite can aid in proper treatment amidst confounding

459 symptoms. In this work, we determined that amplification and a resulting change in diffusivity

460 only occurred in the positive malaria samples (Figure 3). Additionally, we confirmed the

461 specificity of the LAMP assay at various concentrations of blood, discovering that none of the

462 negative controls amplified (Figure S3). This proves that this malaria LAMP assay is specific to

463 the Plasmodium genus.

464 PD-LAMP can also detect malaria at low concentrations from patient samples in 45

465 minutes (Table 1 and Table 2). However, from the first 6 patient samples tested, the 28s rRNA

466 primer set failed to amplify patient ID 3 and ID 4 consistently. The amplification inconsistencies

467 with ID 3 and ID 4 may be due to the low copy number or low copies of the 28s target gene.

468 Conversely, the primer set targeting 18s rRNA successfully amplified all 6 of the same patient

469 samples within 45 minutes. Therefore, we identified that the samples were likely not degraded

470 over time, but rather the difference in gene target copies had a greater effect in ID 3 and ID 4.

471 The use of multiple primer sets, such as $28 \mathrm{~s}$ and $18 \mathrm{~s}$ rRNA targeted primers, could prove useful

472 for multiplexing and targeting multiple regions to combat emerging mutations in malaria

473 DNA.(48) Although the sensitivity of the PD-LAMP device is not superior to the commercial

474 Eiken kit, our method does not require pre-processing steps of the blood sample and works in

475 complex sample matrices.

476 We compared the PD-LAMP method to a variety of well-established malaria detection

477 methods. For example, we demonstrated the ability to detect $P$. falciparum parasites from

478 asymptomatic participants with $89 \%$ sensitivity and $100 \%$ specificity when compared to qPCR 
479 performed on DNA from the same whole blood samples (Table 2). qPCR using DNA extracted 480 from whole blood is comparable to the PD-LAMP method. However, nPCR detected 2 more 481 positive cases than PD-LAMP or qPCR, which could also be a result of PCR irreproducibility at 482 ultra-low parasite densities. qPCR sensitivity is positively correlated with template copy 483 number.(43) Low template numbers are subject to the "Monte Carlo" effect, where the success of 484 a primer annealing and replicating during PCR is random.(49) In samples with high parasite 485 densities, this effect is minimal since the template number is high, so the probability of primer 486 binding, and ultimately replicating, is very high. But, in samples with low parasite densities, 487 template copy number is lower and the probability of binding and replication is much lower, 488 resulting in reduced PCR yield and irreproducible results. The differences seen between nPCR, 489 PD-LAMP and qPCR can be attributed to the difference in the targeted regions for amplification. 490 There were variances in repeats for qPCR and PD-LAMP due to the low concentration of DNA, 491 yet we still detected a sample at a concentration of 1 parasite/ $\mu \mathrm{L}$ that was undetectable by 492 microscopy.

493 The use of PD-LAMP on a smartphone is a promising technique for rapid detection of 494 malaria at the point-of-care, because PD-LAMP eliminates the need for DNA extraction steps or 495 the need to rely on antibody-antigen measurements. Ultimately, a smartphone-enabled hardware 496 device could integrate a portable heating element for a standalone, sample-to-answer, portable 497 diagnostic.(26) Total reaction volumes can also be increased to allow for higher input of blood 498 sample while keeping the overall concentration of blood at 10\%. Additionlly, malaria PD-LAMP 499 applications could also be extended for use with alternative sample matrices, such as dried blood 500 spots and urine, which would provide users to have alternative sample storage and/or perform 
501 non-invasive screening. Future development of malaria PD-LAMP will involve field-testing in

502 low-resource areas and multiplexing for detection of coinfections.

\section{Conclusion}

$504 \quad$ In this work, we demonstrate that we can detect low concentrations of malaria DNA from 505 unprocessed blood samples through the use of a smartphone-enabled device that is robust, 506 portable, and has potential to be used in low-resource settings. We are able to detect down to 3 507 copies $/ \mu$ L from $P$. falciparum DNA. We demonstrate that Plasmodium parasites can be detected 508 from whole blood specifically and robustly with PD-LAMP at concentrations down to 1 509 parasite $/ \mu \mathrm{L}$ with no need for DNA extraction or pre-processing. Further, we detected $P$. 510 falciparum parasites from asymptomatic participants with $89 \%$ sensitivity and 100\% specificity 511 when compared to qPCR measurements from the same samples.

512 Current diagnostics are unable to rapidly and accurately detect parasatimia below 100 513 parasites $/ \mu \mathrm{L}$, which is one reason why there has been poor progress toward the reduction of 514 malaria transmission.(50) The sensitivity of the PD-LAMP device is competitive against field-

515 based testing techniques such as RDTs, Loopamp ${ }^{\mathrm{TM}}$ malaria kit, and white light microscopy.

516 Future work includes incorporating dried reagents on-chip for long term storage and integrating

517 heating into the device to perform the assays all on one handheld platform. Ultimately, a fully

518 integrated PD-LAMP smartphone device could improve public health in malaria endemic areas

519 through rapid low parasitemia detection and aid in process towards eradication of the infectious 520 disease.

\section{Declarations}

\section{Competing interests}


524 Steven T. Wereley, Tamara L. Kinzer-Ursem, Katherine N. Clayton, and Jacqueline C. Linnes are

525 co-founders of OmniVis Inc., a spinout company of Purdue University to translate the smartphone

526 PD-LAMP technology. Dr. Clayton is presently the CEO of OmniVis Inc. All others have declared

527 that they have no competing interests.

528 Ethics Approval and Consent to Participate

529 Written informed consent was obtained from parents or guardians of study participants. Ethical

530 approval was granted by the institutional review boards for human studies at the Makerere

531 University School of Medicine, the Uganda National Council for Science and Technology, and

532 the University of Minnesota Medical School.

533 Consent for publication

534 Not Applicable

535 Availability of Data and Materials

536 The datasets used and/or analyzed during the current study are available from the corresponding

537 author on reasonable request.

538 Author Contributions

539 AC and KC developed the study. AC performed all LAMP studies. KC selected samples for the

540 study. GC and KC carried out all PCR work. AC and DHL performed PD on samples and

541 analyzed the results. AC, KC and KNC drafted the manuscript. JC,SW,CJ and TKU critically

542 revised the manuscript. All authors read and approved the final manuscript.

\section{Funding}

545 This work was supported in part by the Vodafone Americas Foundation Wireless Innovation

546 Project Award (TKU and JCL), Purdue Global Engineering Programs Innovations 
547 in International Development Lab (I2D) (TKU and JCL), Indiana Clinical and Translational

548 Sciences Institute funded, in part by Award Number UL1TR002529 from the National Institutes

549 of Health, National Center for Advancing Translational Sciences, Clinical and Translational

550 Sciences Award, and the George Washington Carver Fellowship. The content is solely the

551 responsibility of the authors and does not necessarily represent the official views of the National

552 Institutes of Health and other funding institutions. Patient and study participant samples were

553 obtained from a study supported by the National Institute of Neurological Disorders and Stroke

554 (R01NS055349).

555 Acknowledgements

556 We would like to acknowledge Taylor Moehling and Seba Kaakeh for their work

557 in malaria LAMP primer design and optimization as well as Lindsey Turnbull. We

558 thank Dibyadyuti Datta for their malaria expertise and input.

\section{References}

562 1. WHO. World Malaria Report 2019 [Internet]. World Health Organization, editor. Geneva; 2019 [cited 2020 Apr 1]. 1-232 p. Available from: https://www.who.int/publications-detail/worldmalaria-report-2019

2. WHO. World Malaria Report 2018 [Internet]. World Health Organization, editor. Geneva; 2018.

166 p. Available from: www.who.int/malaria

3. Reboud J, Xu G, Garrett A, Adriko M, Yang Z, Tukahebwa EM, et al. Paper-based microfluidics for DNA diagnostics of malaria in low resource underserved rural communitie. Proc Natl Acad Sci U S A [Internet]. 2018 [cited 2019 Apr 23];116(11):4834-42. Available from: www.pnas.org/lookup/suppl/doi:10.

4. Health Organization W. HPV and cervical cancer in the 2007 report. Vaccine [Internet]. 2007;25 Suppl 3. Available from: www.who.int/malaria

5. Roth JM, Korevaar DA, Leeflang MMG, Mens PF. Molecular malaria diagnostics: A systematic review and meta-analysis. Crit Rev Clin Lab Sci. 2016;53(2):87-105.

6. Birhanie M, Tessema B, Ferede G, Endris M, Enawgaw B. Malaria, Typhoid Fever, and Their 
7. Males S, Gaye O, Garcia A. Long-term asymptomatic carriage of Plasmodium falciparum protects from malaria attacks: A prospective study among Senegalese children. Clin Infect Dis [Internet]. 2008 Feb 15 [cited 2020 Sep 21];46(4):516-22. Available from: https://academic.oup.com/cid/article-lookup/doi/10.1086/526529

8. of Vector Borne Disease J. High prevalence of asymptomatic malaria in apparently healthy

10. Gbalégba CGN, Ba H, Silué KD, Ba O, Tia E, Chouaibou M, et al. Distribution of Plasmodium schoolchildren in Aliero, Kebbi state, Nigeria [Internet]. [cited 2020 Sep 21]. Available from: https://www.researchgate.net/publication/263297015

9. Villalta F, Flores-Valdez MA, Yu X, Feng Y, Borgman S. Asymptomatic Malaria in School Children and Evaluation of the Performance Characteristics of the Partec Cyscope $\square$ in the Mount Cameroon Region. J Bacteriol Parasitol [Internet]. 2012 [cited 2020 Sep 21];3:7. Available from: http://dx. spp. infection in asymptomatic carriers in perennial and low seasonal malaria transmission settings in West Africa. Infect Dis Poverty [Internet]. 2018 Dec 25 [cited 2020 Sep 21];7(1):39. Available from: https://idpjournal.biomedcentral.com/articles/10.1186/s40249-018-0412-9

11. Chen I, Clarke SE, Gosling R, Hamainza B, Killeen G, Magill A, et al. "Asymptomatic" Malaria: A Chronic and Debilitating Infection That Should Be Treated. 2016;

12. Kolluri N, Klapperich CM, Cabodi M. Towards lab-on-a-chip diagnostics for malaria elimination [Internet]. Vol. 18, Lab on a Chip. 2018 [cited 2019 Apr 24]. p. 75-94. Available from: https://pubs.rsc.org/en/content/articlepdf/2018/lc/c7lc00758b

13. Bousema T, Okell L, Felger I, Drakeley C. Asymptomatic malaria infections: Detectability, transmissibility and public health relevance [Internet]. Vol. 12, Nature Reviews Microbiology. 2014 [cited 2018 Sep 10]. p. 833-40. Available from: www.nature.com/reviews/micro

14. Safavieh M, Ahmed MU, Ng A, Zourob M. High-throughput real-time electrochemical monitoring of LAMP for pathogenic bacteria detection. Biosens Bioelectron [Internet]. 2014 Aug 15 [cited 2019 Apr 24];58:101-6. Available from: https://www.sciencedirect.com/science/article/pii/S0956566314000803?via\%3Dihub

15. Wongsrichanalai C, Barcus MJ, Muth S, Sutamihardja A, Wernsdorfer WH. A review of malaria diagnostic tools: Microscopy and rapid diagnostic test (RDT). Am J Trop Med Hyg [Internet]. 2007 [cited 2018 Sep 10];77(SUPPL. 6):119-27. Available from: www.malaria.mr4.org

16. Sirichaisinthop J, Buates S, Watanabe R, Han ET, Suktawonjaroenpon W, Krasaesub S, et al. Short report: Evaluation of loop-mediated isothermal amplification (LAMP) for malaria diagnosis in a field setting. Am J Trop Med Hyg. 2011;85(4):594-6.

17. Milne LM, Kyi MS, Chiodini PL, Malaria PHLS, Warhurst DC. Accuracy of routine laboratory diagnosis of malaria in the United Kingdom. J Clin Pathol. 1994;47(8):740-2.

18. Hänscheid T, Grobusch MP. How useful is PCR in the diagnosis of malaria? Trends Parasitol [Internet]. 2002 Sep 1 [cited 2019 Apr 23];18(9):395-8. Available from: http://www.ncbi.nlm.nih.gov/pubmed/12377256

19. Ndao M, Bandyayera E, Kokoskin E, Gyorkos TW, Dick Maclean J, Ward BJ. Comparison of Blood Smear, Antigen Detection, and Nested-PCR Methods for Screening Refugees from Regions Where Malaria Is Endemic after a Malaria Outbreak in Quebec, Canada. J Clin Microbiol [Internet]. 2004 [cited 2019 Aug 5];42(6):2694-700. Available from: 
https://www.ncbi.nlm.nih.gov/pmc/articles/PMC427867/pdf/1934-03.pdf

622 20. Stemple CC, Angus S V., Park TS, Yoon J-Y. Smartphone-Based Optofluidic Lab-on-a-Chip for Detecting Pathogens from Blood. J Lab Autom [Internet]. 2014 Feb 21 [cited 2019 Apr 24];19(1):35-41. Available from: http://journals.sagepub.com/doi/10.1177/2211068213498241

625

626

627

628

629

630

631

632

633

634

635

636

637

638

639

640

641

642

643

644

645

646

647

648

649

650

651

652

653

654

655

656

657

658

659

660

661

662

663

21. Das S, Jang IK, Barney B, Peck R, Rek JC, Arinaitwe E, et al. Performance of a High-Sensitivity Rapid Diagnostic Test for Plasmodium falciparum Malaria in Asymptomatic Individuals from Uganda and Myanmar and Naive Human Challenge Infections. Am J Trop Med Hyg [Internet]. 2017 Nov 8 [cited 2019 May 1];97(5):1540-50. Available from: http://www.ajtmh.org/content/journals/10.4269/ajtmh.17-0245

22. Jimenez A, Rees-Channer RR, Perera R, Gamboa D, Chiodini PL, González IJ, et al. Analytical sensitivity of current best-in-class malaria rapid diagnostic tests. Malar J. 2017;16(1):1-9.

23. Modak SS, Barber CA, Geva E, Abrams WR, Malamud D, Serge Y, et al. Rapid Point-of-Care Isothermal Amplification Assay for the Detection of Malaria without Nucleic Acid Purification. Infect Dis Res Treat [Internet]. 2016 [cited 2018 Sep 10];9:1-9. Available from: http://journals.sagepub.com/doi/pdf/10.4137/IDRT.S32162

24. Mbanefo A, Kumar N. Evaluation of Malaria Diagnostic Methods as a Key for Successful Control and Elimination Programs. Trop Med Infect Dis. 2020;5(2):102.

25. Zanoli LM, Spoto G. Isothermal amplification methods for the detection of nucleic acids in microfluidic devices. Biosensors. 2013;3(1):18-43.

26. Phillips E, Moehling T, Ejendal K, Hoilett O, Byers K, Basing LA, et al. Microfluidic Rapid and Autonomous Analytical Device (microRAAD) to Detect HIV from Whole Blood Samples. bioRxiv [Internet]. 2019 [cited 2019 Dec 2];582999. Available from: http://dx.doi.org/10.1101/582999

27. Mori Y, Notomi T. Loop-mediated isothermal amplification (LAMP): a rapid, accurate, and costeffective diagnostic method for infectious diseases. J Infect Chemother [Internet]. 2009 Apr 1 [cited 2019 Apr 23];15(2):62-9. Available from: http://www.ncbi.nlm.nih.gov/pubmed/19396514

28. Selvarajah D, Naing C, Htet NH, Mak JW. Loop-mediated isothermal amplification (LAMP) test for diagnosis of uncomplicated malaria in endemic areas: a meta-analysis of diagnostic test accuracy. Malar J [Internet]. 2020;19(1):211. Available from: https://doi.org/10.1186/s12936-02003283-9

29. Modak SS, Barber CA, Geva E, Abrams WR, Malamud D, Serge Y, et al. Rapid Point-of-Care Isothermal Amplification Assay for the Detection of Malaria without Nucleic Acid Purification.

30. Hayashida K, Kajino K, Hachaambwa L, Namangala B, Sugimoto C. Direct Blood Dry LAMP: A Rapid, Stable, and Easy Diagnostic Tool for Human African Trypanosomiasis. PLoS Negl Trop Dis [Internet]. 2015 Mar 13 [cited 2021 Jan 11];9(3). Available from: /pmc/articles/PMC4358998/?report=abstract

31. Tegegne B, Getie S, Lemma W, Mohon AN, Pillai DR. Performance of loop-mediated isothermal amplification (LAMP) for the diagnosis of malaria among malaria suspected pregnant women in Northwest Ethiopia. Malar J [Internet]. 2017 [cited 2019 Apr 23];16:34. Available from: https://www.ncbi.nlm.nih.gov/pmc/articles/PMC5244525/pdf/12936_2017_Article_1692.pdf

32. Mori Y, Nagamine K, Tomita N, Notomi T. Detection of Loop-Mediated Isothermal Amplification Reaction by Turbidity Derived from Magnesium Pyrophosphate Formation. Biochem Biophys Res Commun [Internet]. 2001 Nov 23 [cited 2019 Apr 24];289(1):150-4. 
33. Kwon L, Long KD, Wan Y, Yu H, Cunningham BT. Medical diagnostics with mobile devices: Comparison of intrinsic and extrinsic sensing. Biotechnol Adv [Internet]. 2016 May 1 [cited 2019 Apr 24];34(3):291-304. Available from: 34. Liu C, Mauk MG, Hart R, Bonizzoni M, Yan G, Bau HH. A Low-Cost Microfluidic Chip for
Rapid Genotyping of Malaria-Transmitting Mosquitoes. Michel K, editor. PLoS One [Internet]. 2012 Aug 3 [cited 2019 Apr 24];7(8):e42222. Available from: https://dx.plos.org/10.1371/journal.pone.0042222

35. Clayton KN, Moehling TJ, Hoon Lee D, Wereley ST, Linnes JC, Kinzer-Ursem TL. Particle Diffusometry: An Optical Detection Method for Vibrio cholerae Presence in Environmental Water Samples OPEN. Sci Rep [Internet]. 2019 [cited 2019 May 1];9. Available from: https://doi.org/10.1038/s41598-018-38056-7

36. Sattabongkot J, Tsuboi T, Han ET, Bantuchai S, Buates S. Loop-mediated isothermal amplification assay for rapid diagnosis of malaria infections in an area of endemicity in Thailand. J Clin Microbiol [Internet]. 2014 [cited 2018 Sep 18];52(5):1471-7. Available from: http://jcm.asm.org/

37. Moehling TJ, Lee DH, Henderson ME, McDonald MK, Tsang PH, Kaakeh S, et al. A Smartphone-Based Particle Diffusometry Platform for Sub-Attomolar Detection of Vibrio cholerae in Environmental Water. Biosens Bioelectron. 2020 Nov 1;167:112497.

38. Lau YL, Lai MY, Fong MY, Jelip J, Mahmud R. Loop-mediated isothermal amplification assay for identification of five human plasmodium species in Malaysia. Am J Trop Med Hyg. 2016;94(2):336-9.

39. Bangirana P, Opoka RO, Boivin MJ, Idro R, Hodges JS, Romero RA, et al. Severe Malarial Anemia is Associated With Long-term Neurocognitive Impairment. Clin Infect Dis [Internet]. 2014 Aug 1 [cited 2019 Sep 26];59(3):336-44. Available from: https://academic.oup.com/cid/article-lookup/doi/10.1093/cid/ciu293

40. Hofmann N, Mwingira F, Shekalaghe S, Robinson LJ, Mueller I, Felger I. Ultra-Sensitive Detection of Plasmodium falciparum by Amplification of Multi-Copy Subtelomeric Targets. PLoS Med [Internet]. 2015 Mar [cited 2019 Sep 10];12(3):e1001788. Available from: http://www.ncbi.nlm.nih.gov/pubmed/25734259

41. Costa DC, Madureira AP, Amaral LC, Sanchez BAM, Gomes LT, Fernandes Fontes CJ, et al. Submicroscopic malaria parasite carriage: How reproducible are polymerase chain reaction-based methods? Mem Inst Oswaldo Cruz. 2014;109(1):21-8.

42. Haanshuus CG, Mørch K, Blomberg B, Strøm GEA, Langeland N, Hanevik K, et al. Assessment of malaria real-time PCR methods and application with focus on lowlevel parasitaemia. PLoS One. 2019;14(7):1-15.

43. Thompson TA, Touré MB, Sanogo D, Shaffer JG, Doumbia SO, Krogstad DJ. Template copy number and the sensitivity of quantitative PCR for Plasmodium falciparum in asymptomatic individuals. Malar J [Internet]. 2020;19(1):1-12. Available from: https://doi.org/10.1186/s12936020-03365-8

44. Vásquez AM, Zuluaga L, Tobón A, Posada M, Vélez G, González IJ, et al. Diagnostic accuracy of loop-mediated isothermal amplification (LAMP) for screening malaria in peripheral and placental 
blood samples from pregnant women in Colombia. Malar J. 2018 Jul 13;17(1).

45. Cook J, Aydin-Schmidt B, González IJ, Bell D, Edlund E, Nassor MH, et al. Loop-mediated isothermal amplification (LAMP) for point-of-care detection of asymptomatic low-density malaria parasite carriers in Zanzibar. 2011 [cited 2017 Sep 13]; Available from: https://malariajournal.biomedcentral.com/track/pdf/10.1186/s12936-015-0573$\mathrm{y}$ ?site $=$ malariajournal.biomedcentral.com

46. Mwesigwa J, Slater H, Bradley J, Saidy B, Ceesay F, Whittaker C, et al. Field performance of the malaria highly sensitive rapid diagnostic test in a setting of varying malaria transmission. Malar $\mathbf{J}$ [Internet]. 2019 [cited 2019 Dec 20];18:288. Available from: https://doi.org/10.1186/s12936-0192929-1

47. Islam MN, ZulKifle M, Sherwani AMK, Ghosh SK, Tiwari S. Prevalence of malaria, dengue and chikungunya significantly associated with mosquito breeding sites. J Islam Med Assoc North Am. 2011 Aug 10;43(2):58.

48. Proux S, Suwanarusk R, Barends M, Zwang J, Price RN, Leimanis M, et al. Considerations on the use of nucleic acid-based amplification for malaria parasite detection. Malar J [Internet]. 2011 [cited 2019 Nov 4];10. Available from: http://www.malariajournal.com/content/10/1/323

49. Karrer EE, Lincoln JE, Hogenhout S, Bennett AB, Bostock RM, Martineau B, et al. In situ isolation of mRNA from individual plant cells: Creation of cell- specific cDNA libraries. Proc Natl Acad Sci U S A [Internet]. 1995 [cited 2020 Sep 21];92(9):3814-8. Available from: /pmc/articles/PMC42052/?report=abstract

50. Moonen B, Cohen JM, Snow RW, Slutsker L, Drakeley C, Smith DL, et al. Operational strategies to achieve and maintain malaria elimination. Lancet [Internet]. 2010 Nov 6 [cited 2019 May 2];376(9752):1592-603. Available from: https://www.sciencedirect.com/science/article/pii/S014067361061269X

51. Clayton KN, Salameh JW, Wereley ST, Kinzer-Ursem TL, Kinzer TL, Kinzer-Ursem TL. Physical characterization of nanoparticle size and surface modification using particle scattering diffusometry. Biomicrofluidics [Internet]. 2016 Sep 1 [cited 2018 Jun 18];10(5):054107. Available from: http://aip.scitation.org/doi/10.1063/1.4962992

52. Clayton KN, Berglund GD, Linnes JC, Kinzer-Ursem TL, Wereley ST. DNA Microviscosity Characterization with Particle Diffusometry for Downstream DNA Detection Applications. Anal Chem. 2017;89(24):13334-41.

53. Clayton KN, Lee DH, Wereley ST, Kinzer-Ursem TL. Measuring biotherapeutic viscosity and degradation on-chip with particle diffusometry. Lab Chip [Internet]. 2017 Aug 22 [cited 2017 Sep 24];17(23):4148-59. Available from: https://www.biorxiv.org/content/early/2017/08/22/179101

54. Olsen MG, Adrian RJ. Out-of-focus effects on particle image visibility and correlation in microscopic particle image velocimetry. In: Experiments in Fluids. 2000.

55. Einstein A. Über einen die Erzeugung und Verwandlung des Lichtes betreffenden heuristischen Gesichtspunkt. Ann Phys [Internet]. 1905 [cited 2021 Jan 11];322(6):132-48. Available from: http://doi.wiley.com/10.1002/andp.19053220607

56. Sie YS, Chuang HS. A micro-volume viscosity measurement technique based on $\mu$ PIV diffusometry. Microfluid Nanofluidics [Internet]. 2014 [cited 2021 Jan 11];16(1-2):65-72. Available from: https://researchoutput.ncku.edu.tw/zh/publications/a-micro-volume-viscositymeasurement-technique-based-on- $\mu$ piv-diff 
57. Snounou G, Singh B. Nested PCR analysis of Plasmodium parasites. Methods Mol Med. 2002;72:189-203.

58. Bharti AR, Patra KP, Chuquiyauri R, Kosek M, Gilman RH, Llanos-Cuentas A, et al. Short Report: Polymerase Chain Reaction Detection of Plasmodium vivax and Plasmodium falciparum DNA from Stored Serum Samples: Implications for Retrospective Diagnosis of Malaria. Vol. 77, Am. J. Trop. Med. Hyg. 2007.

59. Gardner MJ, Hall N, Fung E, White O, Berriman M, Hyman RW, et al. Genome sequence of the human malaria parasite Plasmodium falciparum. Nature [Internet]. 2002 [cited 2017 Aug 29]; Available from: https://www.ncbi.nlm.nih.gov/pmc/articles/PMC3836256/pdf/emss-54165.pdf 


\section{Figures}

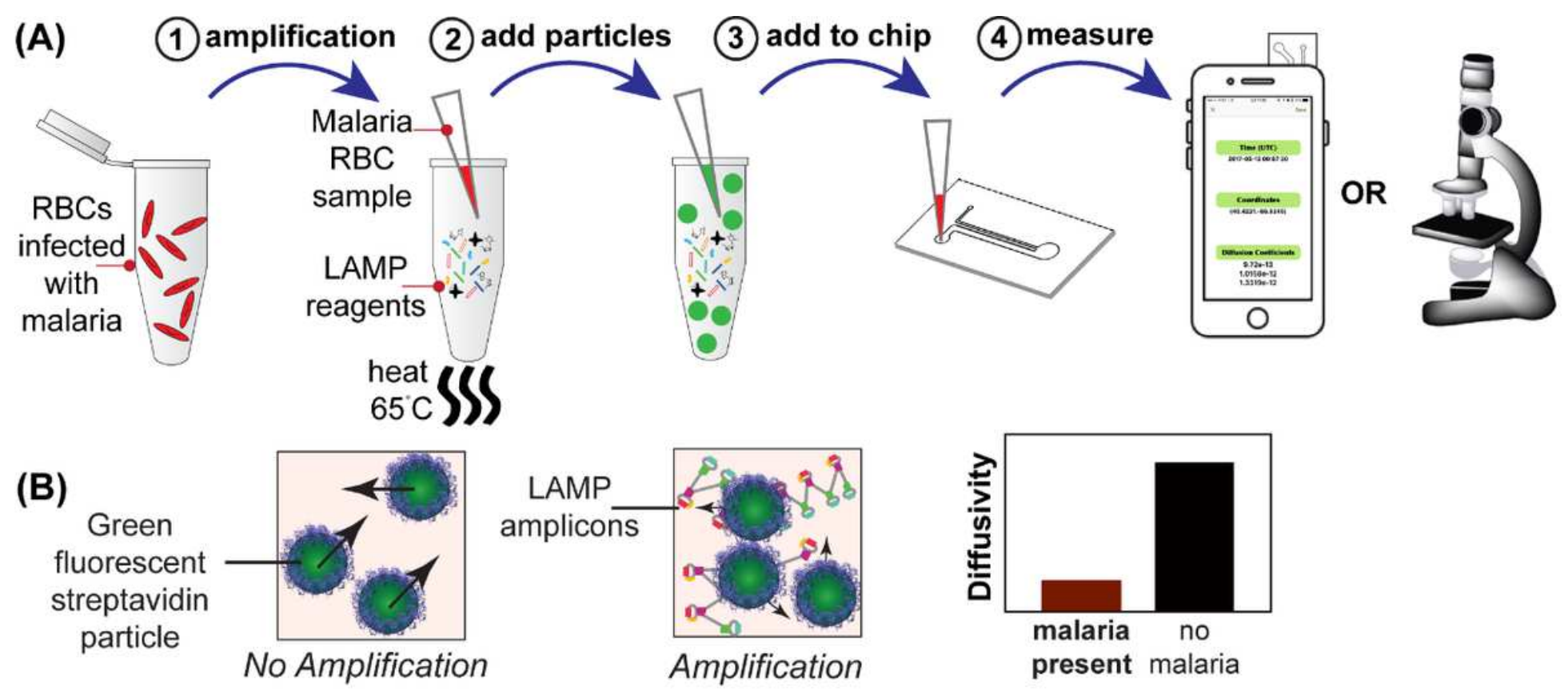

\section{Figure 1}

Illustration of PD-LAMP set-up. (A) LAMP was performed with whole blood samples added directly to the assay reagents. (A1) The red blood cells lysed upon heating, releasing the malaria DNA and initiating the LAMP reaction. (A2) After LAMP is completed, the amplicons are combined with fluorescent particles and (A3) the mixture was then added to a microfluidic chip. (A4) Imaging of the fluorescent beads took place using an epifluorescent microscope or the smartphone device (developed by Moehling and Lee et al.)(37) (B) The smartphone images the fluorescent particles undergoing Brownian motion for 30 seconds. The particles will exhibit faster Brownian motion in the absence of DNA amplicons. In the presence of malaria DNA, the particle motion will be hindered. The diffusion coefficient value, a numerical measure of Brownian motion, is lower when malaria DNA is amplified than if no malaria DNA is present. 
(A)

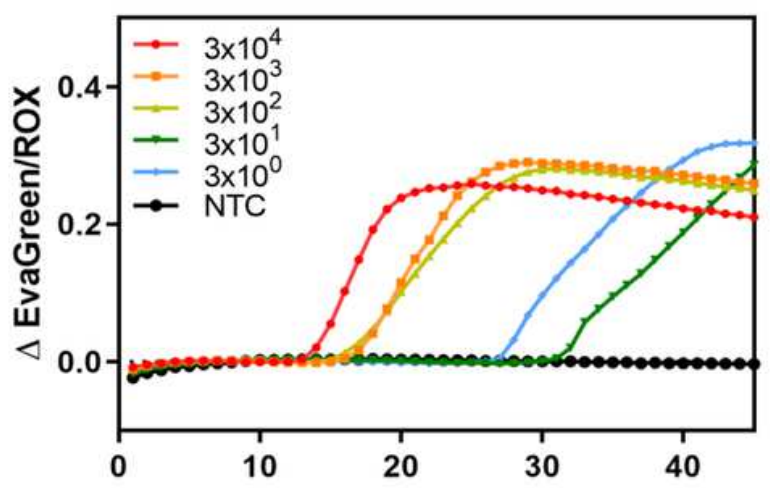

(C)

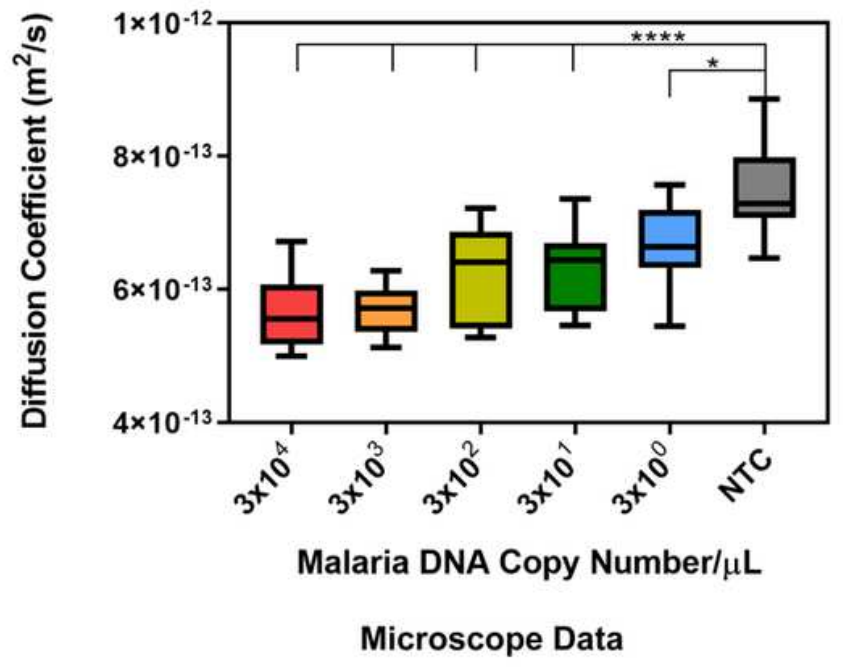

(B)

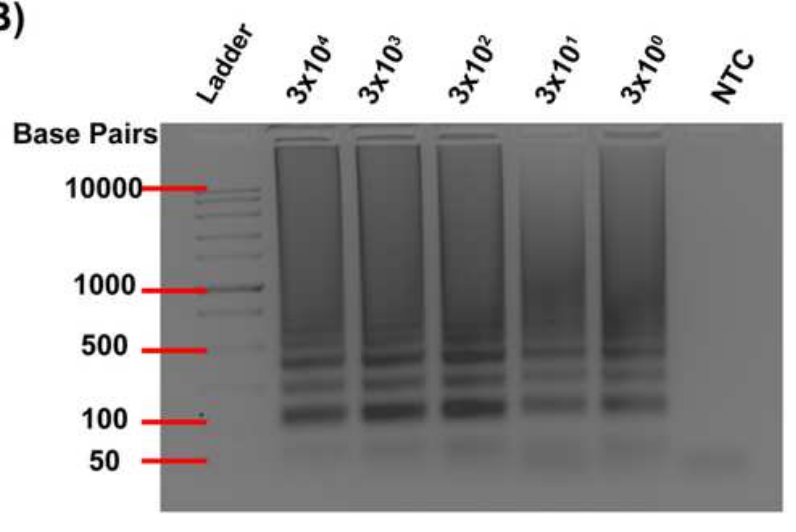

(D)

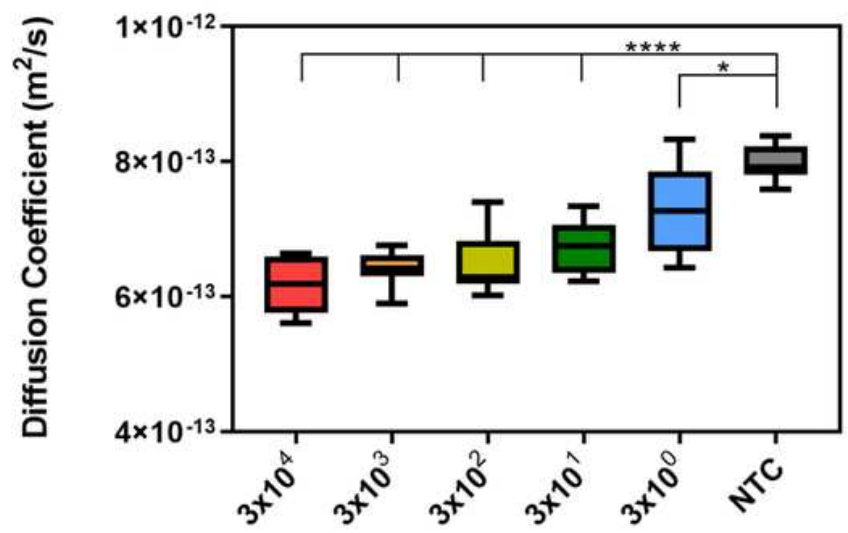

Malaria DNA Copy Number/ $\mu \mathrm{L}$

Phone Data

\section{Figure 2}

P. falciparum genomic DNA detection targeting 28s rRNA. (A) Real-time fluorescence data during a 45minute LAMP reaction with concentrations ranging from $3 \times 104$ to $3 \times 100$ DNA copies $/ \mu \mathrm{L}$. (B) The representative LAMP DNA banding pattern for all positive samples are confirmed in $2 \%$ agarose gel electrophoresis (note the NTC shows no banding pattern). (C) PD analysis from the microscope images of the samples indicates the change in diffusion coefficient for LAMP samples with a statistically significant difference from the negative template control (NTC) for samples with 3x104 -3x101 $(* \star \star \star p<0.0001)$ and $3 \times 100\left({ }^{*} p<0.05\right)$ DNA copies $/ \mu \mathrm{L}$. (D) PD analysis on smartphone device indicates statistically significant differences between $3 \times 104-3 \times 101\left({ }^{* \star *} \mathrm{p}<0.0001\right)$ and $3 \times 100\left({ }^{*} p<0.05\right)$ DNA copies/ $\mu \mathrm{L}$ and the NTC. NTC here represents water added in place of genomic DNA. $(\mathrm{N}=4)$ 
(A)
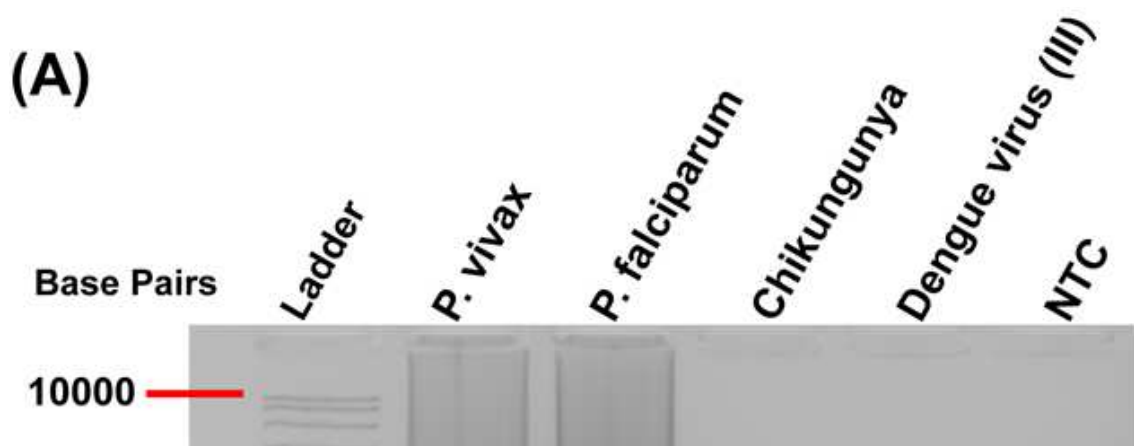

1000

500

100

(B)

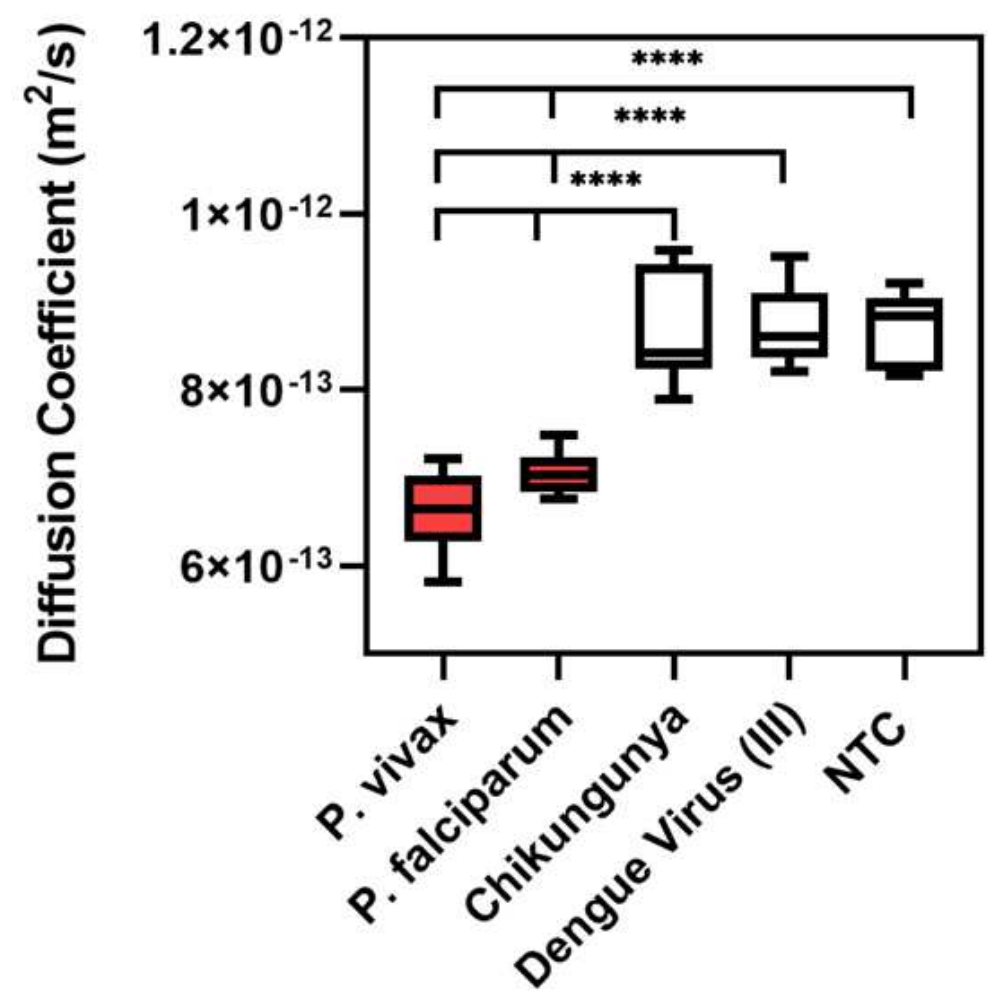

Figure 3

PD-LAMP specificity in $10 \%$ blood. (A) A $2 \%$ agarose gel from LAMP reactions in blood containing malarial strains P. falciparum and P. vivax alongside controls chikungunya and dengue virus (III) at $6 \times 104$ parasites $/ \mu \mathrm{L}$ blood after a 60-minute LAMP reaction. Only malaria samples amplified, demonstrated by the DNA banding pattern in the gel. (B) Diffusion coefficients from smartphone PD analysis, where 
malaria samples showed a significant difference from chikungunya virus, dengue virus (III) and NTC (One-way ANOVA Dunnett's post-hoc test). NTC represents blood without spiked pathogens. $(\mathrm{N}=3)$ Loromisour

(A)

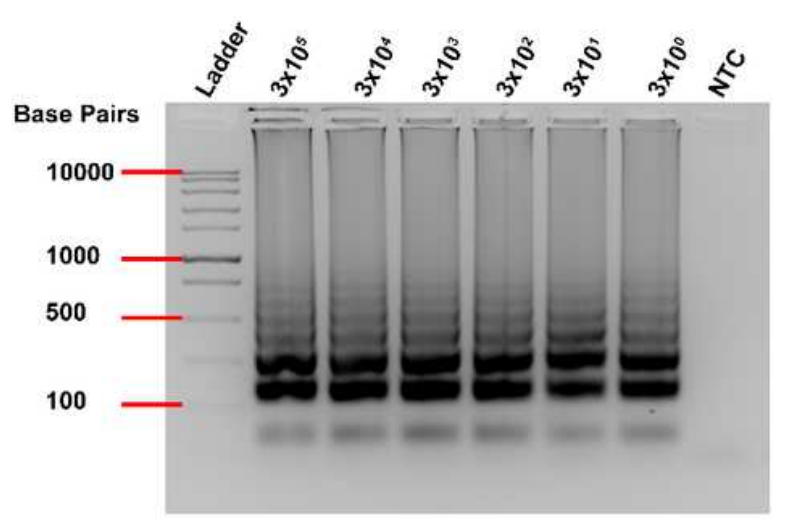

(B)

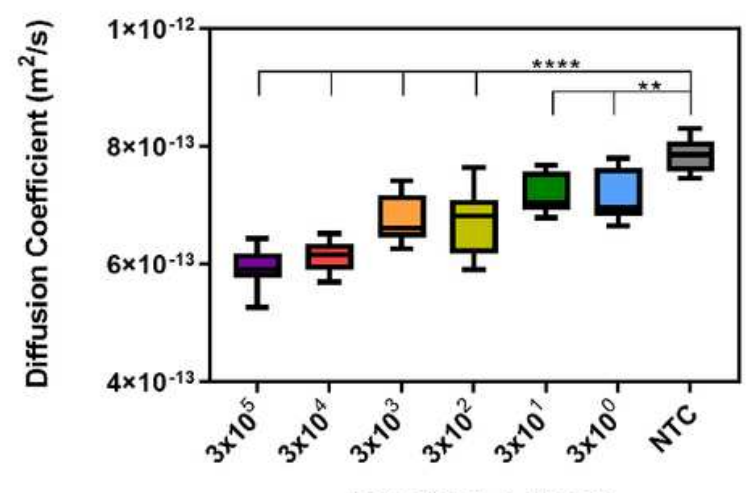

Parasites $/ \mu$ L Blood

\section{Figure 4}

Sensitivity of malaria PD-LAMP with 28 s primers using $10 \%$ blood. (A) $2 \%$ agarose gel confirming amplification in positive samples. (B) Diffusion coefficients measured using smartphone device for dilutions of $3 \times 105-3 \times 100$ of P. falciparum infected blood after a 75-minute reaction. PD analysis shows statistical difference from controls for $3 \times 105-3 \times 102$ parasites $/ \mu \mathrm{L}$ blood $(* * \star * p<0.0001)$ and $3 \times 101-3 \times 100$ parasites/ $\mu \mathrm{L}$ blood $(* * \mathrm{p}<0.001) .(\mathrm{N}=4)$.

(A)

Parasites $/ \mu \mathrm{L}$ :

12.6
0.1260 .0126 NTC NTC

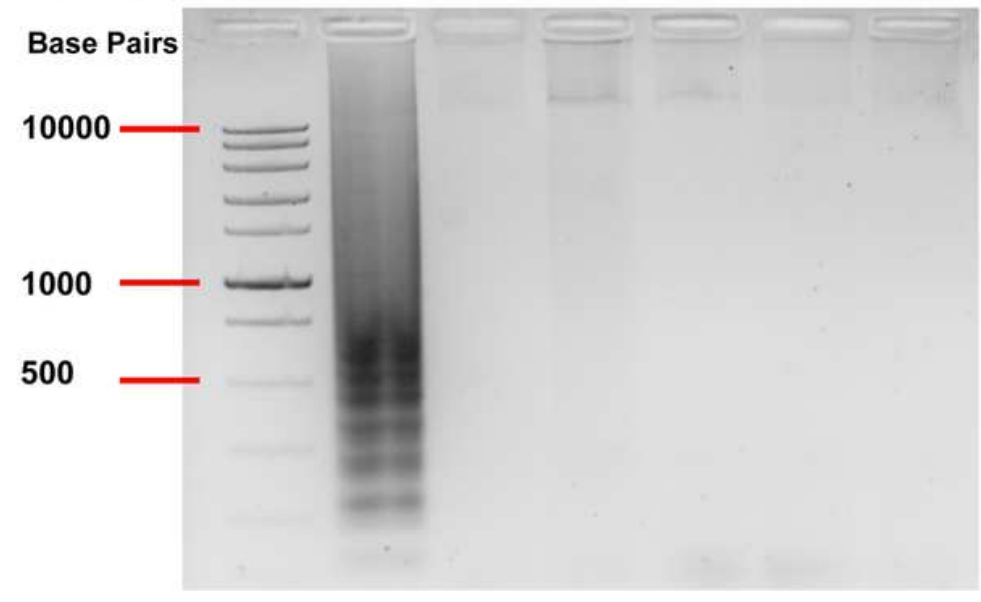

(B)

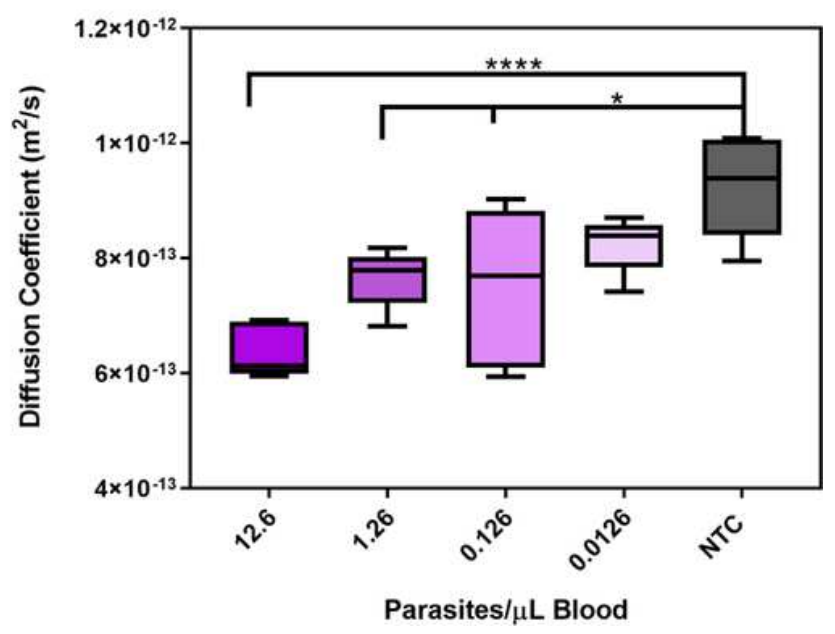

\section{Figure 5}

Serial dilutions of patient ID 2 for the determination of the LOD in patient samples using 18 s primers. (A) A representative gel from dilutions of ID 2 with concentrations ranging from 12.6 to 0.0126 parasites $/ \mu \mathrm{L}$. Only the 12.6 parasites $/ \mu \mathrm{L}$ sample showed consistent amplification in gel represented by the dark smeared banding. (B) Diffusion coefficients from smartphone PD analysis of diluted samples yielded a 
LOD of 0.126 parasites $/ \mu \mathrm{L}$ blood. All dilutions, 12.6 parasites $/ \mu \mathrm{L}$ blood ( $(\star \star \star p<0.0001), 1.26$ and 0.126 parasites $/ \mu \mathrm{L}$ blood $\left({ }^{*} \mathrm{p}<0.05\right)$, except 0.0126 parasites $/ \mu \mathrm{L}$ blood were found to be statistically different from NTC. $(\mathrm{N}=3)$

\section{Supplementary Files}

This is a list of supplementary files associated with this preprint. Click to download.

- SupportingInformation.docx 